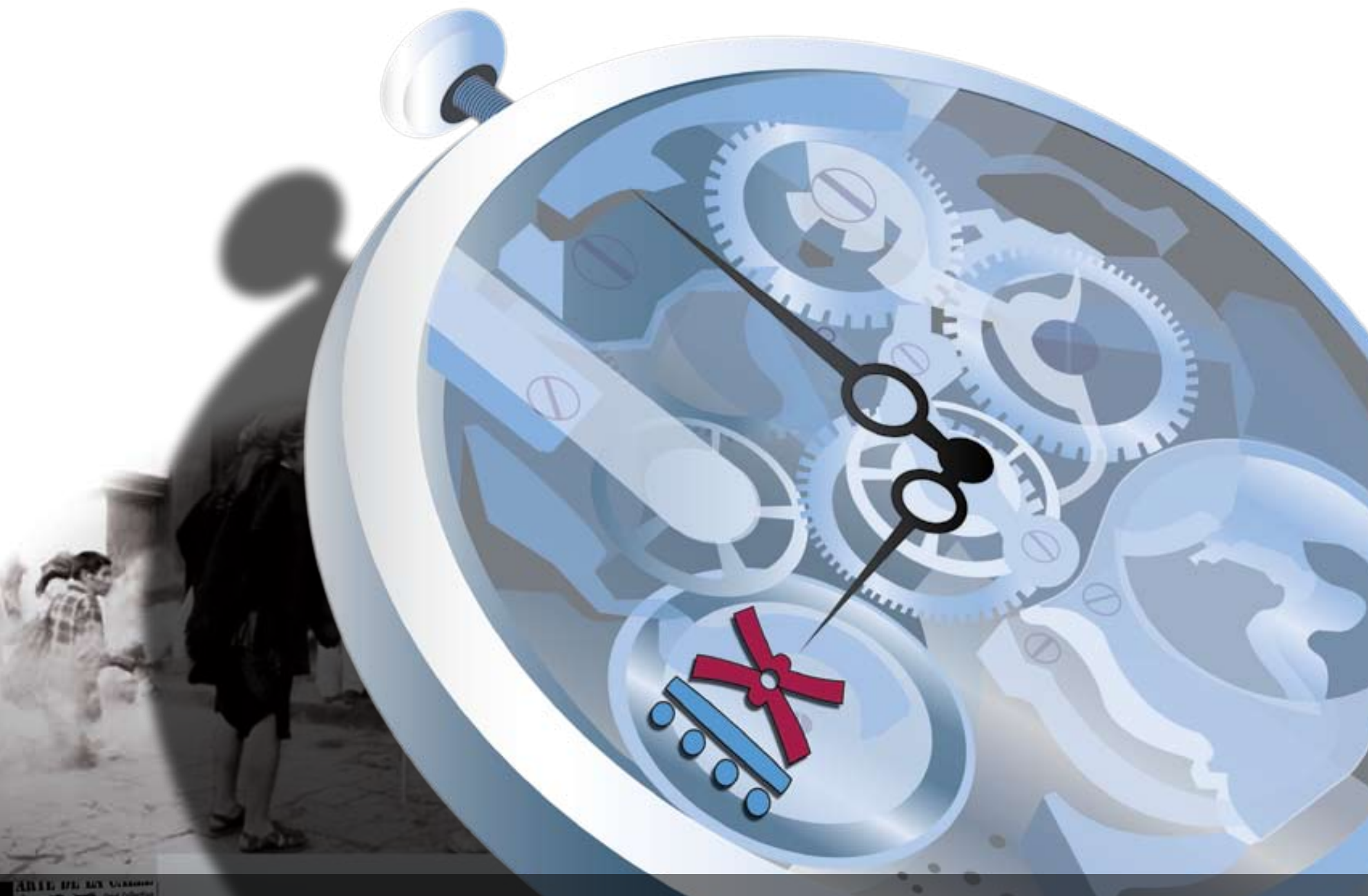

$\lambda 9^{\circ}$ CONGRESO \% CENTROAMERICANO DE HISTORIA
ISSN 1409-469X

Fecha de recepción: 15 de mayo 2008 Fecha de aceptación: 30 de mayo 2008

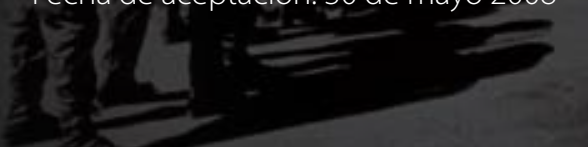

Memorias Comunistas sobre la Guerra Civil de 1948 en Costa Rica

Miembros del Consejo Editorial:

Dr. Ronny Viales, Dr. Juan José Marín

Editores Técnicos:

Allan Fonseca, Andrés Cruz, Gabriela Soto
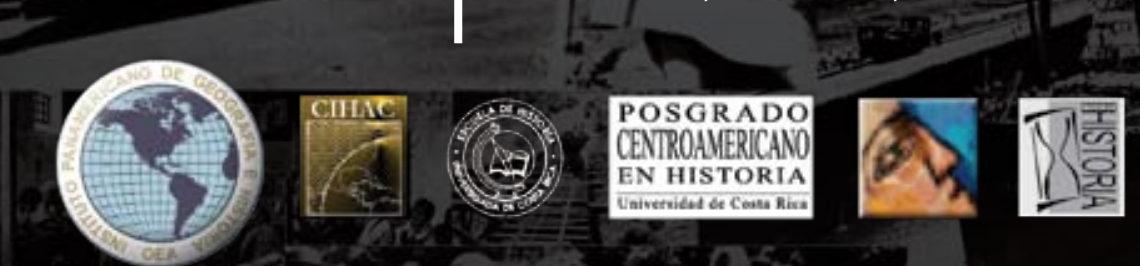
Indexaciones: Repositorio de Revistas UCR, DIALNET, Latindex, REDALYC Directorio y recolector de recursos digitales del Ministerio de Cultura de España, Directory of Open Access Journals. Diálogos Revista Electrónica de Historia ISSN 1409- 469X. Número especial 2008. Dirección web: http://historia.fcs.ucr.ac.cr/dialogos.htm

\title{
Memorias Comunistas sobre la Guerra Civil de 1948 en Costa Rica
}

\author{
David Díaz Arias
}

Candidato al Doctorado en Historia de Indiana University (Bloomington) y profesor de las escuelas de Historia y Estudios Generales de la Universidad de Costa

Rica Correo Electrónico: ddiazari@indiana.edu 


\section{Memorias Comunistas sobre la Guerra Civil de 1948 en Costa Rica ${ }^{1}$}

David Díaz Arias

Después de finalizada la Guerra Civil de 1948, comenzaron una serie de intentos por recuperar la memoria de los acontecimientos y los grupos que la habían producido. Así, el periódico La Nación dio origen a una primera narrativa pública titulada "Sangre, Sudor y Lágrimas", un título que al parecer pretendía recuperar no sólo el famoso discurso de Churchill llamando a luchar contra la Alemania nazi, sino también la traducción al español de la película “In Which We Serve", estrenada en 1942. ${ }^{2}$ Esta serie de relatos se basaba en las experiencias de algunos participantes y fue publicada a partir de mayo de 1948 bajo el seudónimo de Barnaby, quien realmente era el joven socialdemócrata Alberto Cañas. ${ }^{3}$ Era la memoria de los triunfadores

1 Este trabajo constituye un avance de uno de los capítulos de mi tesis doctoral en proceso en el Department of History de Indiana University titulada: "Social Crisis and Struggling Memories: Popular Mobilization, Collective Violence, and the Memories of the Costa Rican Civil War of 1948 ".

2 Se trata de un filme británico de Noel Coward y David Leal en el que se expone el hundimiento del acorazado HMS Torrin. Tras el hundimiento, los marinos sobrevivientes, apesadumbrados y hambrientos, recuerdan sus vidas antes de lanzarse al que podría ser (y lo fue para algunos de sus compañeros) su último viaje. Noel Coward, In which we serve, release script (Inglaterra: British Lion, Two Cities, 1955, originalmente 1942).

3 Alberto Cañas, 80 años no es nada (San José: Editorial de la Universidad de Costa Rica, 2006), p. 214. Otras memorias de los ganadores son: Alberto Cañas, Los ocho años (San José: EUNED, 1982, originalmente publicado en 1955); Henrietta Boggs, Casada con una leyenda. Don Pepe (San José: Gala, 1992); José Figueres Ferrer, El espíritu del 48 (San José: Editorial Costa Rica, 1987); Guillermo Villegas Hoffmeister, De las calles a la guerra (San José: Editorial de la Universidad de Costa Rica, 2001); Guillermo Villegas Hoffmeister, La hora del fin (San José: Editorial de la Universidad de Costa Rica, 2004); Guillermo Villegas Hoffmeister, 
que comenzaba su construcción. Junto a esas memorias triunfantes, otros grupos integrados a los ganadores cuyas expectativas acerca de la sociedad post-bélica no se cumplieron, también lanzaron a la opinión pública su versión de lo ocurrido. ${ }^{4}$ Otro tanto hicieron los perdedores

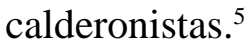

Pero, a su vez, muy pronto, también los más grandes perdedores del conflicto, es decir los comunistas, imprimieron desde la clandestinidad sus primeras interpretaciones de lo que había ocurrido en Costa Rica. Esas narraciones comunistas continuarán apareciendo en las siguientes décadas, hasta constituirse en uno de los ejes centrales de la memoria histórica del 48. En ese sentido, el principal líder de la izquierda, Manuel Mora Valverde, se convertirá en una fuente inagotable de reminiscencias y en un constante revelador de nuevos datos sobre la Guerra Civil. A él se le unirán otras voces de la izquierda, algunas de las cuales caminarán de la mano de las San Isidro de El General en llamas (San José: Editorial de la Universidad de Costa Rica, 2002); Guillermo Villegas Hoffmeister, Testimonios del 48 (San José, Costa Rica: Editorial Costa Rica, 1990); Guillermo Villegas Hoffmeister, Baño de sangre (San José: Editorial de la Universidad de Costa Rica, 2003); José Rafael Cordero Croceri, Memorias de un rebelde (Historia novelada) (Cartago: Editorial Cultural Cartaginesa, 1998); Óscar Cordero Rojas, Diario: ecos de una revolución (San José: Imprenta Española, 1948); Eugenio Rodríguez, Por el camino (San José: EUNED, 1990).

4 Rosendo Argüello, hijo, Quiénes y cómo nos traicionaron (México: S. E., 1954) y Edgar Cardona Quirós, Mi verdad: por el restablecimiento de la verdad histórica: vivencias en 1942, 1944, 1946, 1947, 1948 y 1949 (San José: García Hermanos, 1992).

5 José Albertazzi, La Tragedia de Costa Rica (México: S.E., 1951); Ivonne Clays Spoelder y Guillermo Villegas Hoffmeister, El otro Calderón Guardia (San José: Casa Gráfica, 1985); Teodoro Picado, Memorias (San José: EUNED, 2001); Óscar Barahona Streber, Memorias y opiniones: aspectos de la verdadera historia de la reforma social en Costa Rica y Guatemala, y el pasado, presente, y futuro de la situación económica fiscal de Costa Rica (San José: Editorama, 1996); Óscar Barahona Streber, "En defensa de la verdad histórica: el origen socialcristiano de la legislación social costarricense," Revista Parlamentaria, Vol. 1, No. 4 (1994); Óscar Bákit, Cuentos mariachis. Narraciones de la Guerra Civil del 48 (San José: Editorial Costa Rica, 1990); Fernando Soto Harrison, Qué pasó en los años 40 (San José: EUNED, 1991); Roy Gamero Ruiz and María del Rosario Calderón Fournier, Estadista, médico y hombre. El doctor Calderón Guardia que conocimos y amamos (San José: Trejos Hermanos, 1994). 
memorias del líder comunista, se separarán y finalmente cuestionarán la versión ofrecida por Mora, especialmente en el contexto de la división del Partido Comunista en el primer lustro de la década de 1980.

Aunque existen antecedentes de estudios sobre la reconstrucción del pasado con posterioridad a la Guerra Civil de 1948, ${ }^{6}$ este trabajo ofrece una aproximación al análisis sistemático de las memorias comunistas sobre algunos de los acontecimientos medulares del conflicto bélico más importante que tuvo Costa Rica en el siglo XX y en el que los líderes y militantes de izquierda participaron en primera línea. ${ }^{7}$ Así, se exploran las memorias, entrevistas, y también los folletos partidistas publicados por esos líderes entre 1948 y 1990 . El objetivo fundamental de este artículo es mostrar los principales cambios en esas narraciones y los momentos en que

$6 \quad$ Manuel Solís, La institucionalidad ajena. Los años cuarenta y el fin de siglo (San José: Editorial de la Universidad de Costa Rica, 2006); Alfonso González Ortega, Mujeres y hombres de la posguerra costarricense (1950-1960) (San José: Editorial de la Universidad de Costa Rica, 2005), pp. 1-105; Víctor Hugo Acuña Ortega, "El uso del pasado en el discurso político costarricense: (1940-2002)" (San José: inédito); Mauricio Menjívar Ochoa, "Contienda política y uso del pasado en la Costa Rica de los años 40. La retórica de Rodrigo Facio y José Figueres Ferrer, 1939-1951", en Mauricio Menjívar, Ricardo Argueta y Edgar Solano, Historia y memoria: perspectivas teóricas y metodológicas, Cuadernos de Ciencias Sociales No. 135 (San José: FLACSO, 2005), pp. 49-102, Iván Molina Jiménez, Costarricense por dicha. Identidad nacional y cambio cultural en Costa Rica durante los siglos XIX y XX (San José: Editorial de la Universidad de Costa Rica, 2002), pp. 65-140 y David Díaz Arias, Historia del 11 de abril. Juan Santamaría entre el pasado y el presente (1915-2006) (San José: Editorial de la Universidad de Costa Rica, 2006), pp. 25-120.

7 Este estudio ha encontrado su inspiración metodológica en dos importantes trabajos: Iván Molina Jiménez, Los pasados de la memoria. El origen de la reforma social en Costa Rica (1938-1943) (Heredia: Editorial de la Universidad Nacional, en prensa) y Víctor Hugo Acuña Ortega, Vertientes del recuerdo. Historia y memoria de la guerra contra los filibusteros: Estados Unidos, Nicaragua y Costa Rica (siglos XIX-XXI) (San José: inédito). El trabajo de Molina puede considerar el primer estudio historiográfico que pone a debate las narrativas construidas en torno a lo que ocurrió en la década de 1940, especialmente con respecto a la Reforma Social. Agradezco a los profesores Molina y Acuña por permitirme leer sus valiosos estudios antes de que vean la luz pública. 
se producen desgarres internos en sus exposiciones. Por eso, se han seleccionado seis puntos centrales de los relatos de esos testimonios: 1. El origen del conflicto, 2. El estallido de la guerra civil, 3. La traición del Partido Republicano Nacional, 4. La capitulación de Picado, 5. El Pacto de Ochomogo y 6. Las rupturas en las narrativas comunistas sobre la Guerra Civil que se dan en la década de 1980.

\section{Memorias del origen de la lucha}

Varios meses después de la Guerra Civil de 1948, la Comisión Política del Partido Vanguardia Popular (CPPVP), desde la clandestinidad, publicó un folleto titulado Los Sucesos de Costa Rica. Un examen de la Guerra Civil, un documento que también apareció con el título 
Cómo y por qué cayó la democracia en Costa Rica. ${ }^{8}$ En este trabajo se plantea por primera vez, públicamente la versión comunista sobre lo que había pasado en Costa Rica en 1948. Según la CPPVP, en "la guerra civil de Costa Rica intervinieron factores de tres órdenes: imperialistas, unionistas y de reacción interna de clase contra el movimiento obrero, que había logrado importantes conquistas en los últimos años". ${ }^{9}$

En el "orden imperialista" se exponía la tesis de que el Departamento de Estado de los Estados Unidos intervino en la lucha política y en la guerra civil favoreciendo a los oposicionistas, ya que pretendía asegurarse el posible petróleo que hubiera en suelo costarricense para consorcios petroleros norteamericanos; algo a lo que se adjuntaba la posición geopolítica de Costa Rica tan cercana al Canal de Panamá y tan importante en la posible construcción de un canal futuro en Nicaragua. En el segundo orden, el unionista, los vanguardistas ubicaban a

8 Comisión Política de Vanguardia Popular, Los Sucesos de Costa Rica. Un examen de la Guerra Civil (S.L., S.E., S.A.), Comisión Política de Vanguardia Popular, Cómo y por qué cayó la democracia en Costa Rica (S.L., S.E., S.A.). La única diferencia entre estos textos son tres páginas que aparecen como agregado en la segunda versión mencionada. El título de ese agregado es "Petróleo y Sangre Nativa" y se refiere a la firma de un contrato entre el gobierno provisorio de la Junta Fundadora de la Segunda República y la Honolulu Oil Company. La existencia de dos versiones de este trabajo no es extraña. El dirigente comunista Fernando Chaves Molina indica en uno de sus testimonios que “...recién pasada la guerra se emitió un folleto de crítica, de autocrítica... De él hubo dos ediciones: una se editó en Venezuela y otra se editó creo que en Cuba. Por cierto que a la edición que se hizo en Venezuela se le puso una carátula muy atrayente de una beisbolista con tamañas piernotas y ese fue un error porque cuando llegó aquí al correo vieron aquella muchachota y creyeron que adentro habían más pollos y resulta que era el informe crítico de nuestra actuación en el 48 ... Eso circuló aquí, dos ediciones, claro que aquí se distribuyó una hecho mimeógrafo, pero si hubo impresas dos, recuerdo que están hechas en Venezuela, se la enviamos y se la dirigimos a don Joaquín García Monge". "Todos contra los comunistas. Testimonio del licenciado don Fernando Chaves Molina. Miembro del Comité Central del Partido Vanguardia Popular (Comunista), quien tuvo amplia participación de los hechos de 1948", en Guillermo Villegas Hoffmeister, El gobierno sobre las armas (San José: Editorial de la Universidad de Costa Rica, 2002), pp. 277-278.

9 Comisión Política de Vanguardia Popular, Los Sucesos de Costa Rica, p. 4. 
un "círculo permanente de emigrados de varios países que vivía planeando conspiraciones", cuyo "aventurerismo" y "unionismo" se explicaban "por la extracción social de tales elementos, la falta de ligazón con las masas y las diversidades de nacionalidades alrededor de un mismo problema". ${ }^{10}$ Según la CPPVP, esos emigrados eran apoyados por los Estados Unidos con el objetivo de ganar influencia en esos grupos quienes eventualmente tomarían el poder frente a las antiguas y desacreditas dictaduras que los norteamericanos habían apoyado en el pasado.

En el orden de "reacción de clase" es en donde la CPPVP presta más interés a los factores internos que habrían desencadenado la Guerra Civil de 1948. Y es en este apartado en el que, por primera vez, los comunistas desarrollan una cronología de los sucesos de la década de 1940 y las causas que los llevaron a perderla. En esa cronología, se presta especial atención a una reconstrucción de los factores históricos que convierten a la guerra en la etapa máxima de una lucha de clases que se había venido perfilando desde principios de la década examinada. En ese sentido, los comunistas presentan los acontecimientos de forma tal que convincentemente expliquen la teoría de la lucha de clases. Por eso, el origen de la guerra radicará en la legislación social aprobada durante la administración Calderón Guardia. De acuerdo con la CPPVP:

"No obstante la justicia de todas esas medidas, las clases ricas promovieron una agitación sin precedentes; con poderosos medios de agitación iniciaron en gran escala la falsificación de la opinión pública interna, al amparo de una irrestricta libertad de prensa y con una irresponsabilidad realmente criminal". ${ }^{11}$

La oposición a las reformas sociales, desde esta perspectiva, se llevaría adelante por

10 Comisión Política de Vanguardia Popular, Los Sucesos de Costa Rica, pp. 9-10.

11 Comisión Política de Vanguardia Popular, Los Sucesos de Costa Rica, p. 12. 
medio de una inversión enorme en la prensa tanto en el interior del país como en el exterior, especialmente después de la elección de Teodoro Picado y con un mensaje que exponía al Estado costarricense como tomado por una "tiranía comunista". ${ }^{12}$ Según los comunistas, el ala derecha de la administración Picado se aprovechaba de la legislación social y económica para cometer actos de corrupción y deshonestidad mientras que el Partido Vanguardia Popular (PVP), se enfrentaba a esas "lacras" sin dejar al gobierno en sus manos. Aún así, los comunistas reconocen que cometieron "el error de no ir en grado suficiente a la crítica pública contra todos los actos que le traían desprestigio", quedando en una encrucijada: "la masa oposicionista templaba su fervor en la mística anticomunista y los Ministros y capas del Partido de Gobierno que habían sido atacados por nosotros, se unían a la oposición para aplastarnos". ${ }^{13}$

Hacia 1955, en el contexto del segundo intento fallido de invasión al país por parte de los calderonistas que se encontraban en Nicaragua, los líderes comunistas Carlos Luis Fallas, Eduardo Mora y Arnoldo Ferreto publicaron un folleto titulado Calderón Guardia, José Figueres y Otilio Ulate a la luz de los últimos acontecimientos políticos. ${ }^{14}$ En este texto, escrito con la intención de responder las acusaciones calderonistas que culpaban a los comunistas de traicionar a Calderón Guardia y de "haberse vendido" a Figueres, hay una recapitulación de las condiciones que llevaron a la Guerra Civil. Contrario al análisis de 1948, los vanguardistas se detienen en dar

12 Para un análisis que profundiza en las maneras en que los oposicionistas construyeron la imagen de los gobiernos de los ocho años (1940-1948) como dictaduras, ver: Solís, La institucionalidad ajena, pp. 87-277. Sobre la forma en que los oposicionistas radicados en Estados Unidos convencieron a la opinión pública estadounidense acerca de la legalidad de su lucha frente al gobierno de Teodoro Picado, ver: Kyle Longley, "Peaceful Costa Rica, the First Batleground: the United States and the Costa Rican Revolution of 1948", en The Americas, Vol. 50, No. 2 (October, 1993), pp. 149-175.

13 Comisión Política de Vanguardia Popular, Los Sucesos de Costa Rica, p. 14.

14 Carlos Luis Fallas, Eduardo Mora y Arnoldo Ferreto, Calderón Guardia, José Figueres y Otilio Ulate a la luz de los últimos acontecimientos políticos (San José: s.e., 1955). 
una breve reseña de la historia del Partido Republicano Nacional (PRN, que ubican fundándose en 1901 en vez de 1931) ${ }^{15}$ e identifican a Calderón Guardia como un presidente que llegó "al poder en hombros de banqueros, cafetaleros, ganaderos y grandes comerciantes", pero que se debió volver hacia el pueblo debido al contexto internacional de lucha antifascista y al "reforzamiento de la conciencia democrática nacional" y, sobre todo, debido al "auge del movimiento obrero revolucionario político y sindical". ${ }^{16}$

Justamente, esta visión de dos Calderón Guardia, el de los banqueros anterior a la unidad con los comunistas y el caudillo movilizador de masas posterior a esa unidad, se destacará en las memorias vanguardistas. ${ }^{17}$ Así, el cambio de Calderón representado en la legislación social, habría convertido al PRN en un "partido de masas populares, inquietadas por postulados de vanguardia", pero conservando una dirigencia que, con excepción de Calderón, "eran enemigos de la nueva política social que aceptaron a regañadientes y con la intención de sabotearla". ${ }^{18}$ Es a esta dirigencia a la que los líderes vanguardistas le achacan los errores políticos cometidos por Calderón entre 1942 y 1948. En esa narrativa, es como si el caudillo Calderón, construido por los comunistas, sufriera una descaudillización cada vez que se aproxima a los grupos de derecha y se aleja de la influencia de Vanguardia Popular. Ese "otro" Calderón modifica la imagen del caudillo en las memorias comunistas hasta llegar a representarlo como intransigente durante la 15 Esta fecha errónea que vuelve sinónimo al Partido Republicano Nacional con el Partido Republicano (fundado en 1897), como lo ha identificado Iván Molina, se volvió común en muchos estudios históricos que se han referido a la historia del PRN. Iván Molina Jiménez, Los pasados de la memoria. El origen de la reforma social en Costa Rica (1938-1943) (Heredia: Editorial de la Universidad Nacional, en prensa), capítulo 3, nota 3.

16 Fallas, Mora y Ferreto, Calderón Guardia, José Figueres y Otilio Ulate a la luz de los últimos acontecimientos políticos, p. 29.

17 La invención del calderonismo y del caldero-comunismo constituye una parte importante del capítulo primero del trabajo señalado en la nota 1 de este estudio.

18 Fallas, Mora y Ferreto, Calderón Guardia, José Figueres y Otilio Ulate a la luz de los últimos acontecimientos políticos, p. 30. 
coyuntura bélica. ${ }^{19}$

Tres años después de la publicación de Fallas, Mora y Ferreto, Manuel Mora escribió, difundió por radio y luego publicó como folleto un texto titulado: Dos discursos en defensa de Vanguardia Popular. ${ }^{20}$ El primer discurso fue pronunciado en Radio Monumental el 30 de enero de 1958 con el objetivo de enfrentar una alocución de Otilio Ulate, mientras que el segundo se difundió por medio de Radio La Voz del Trópico como una reacción a un discurso de José Figueres. De acuerdo con Manuel Mora, estos discursos le dieron la oportunidad de hablar públicamente después de "diez años de silencio obligado". ${ }^{21}$ En estos textos Mora sostiene que la oposición a la Reforma Social la comenzó Otilio Ulate como una reacción a la unidad de los comunistas con Calderón Guardia. Ulate, según Mora, habría seguido ese camino con el interés de recibir el apoyo político-electoral de "todas las fuerzas reaccionarias del país", ${ }^{22}$ Lo más llamativo de esta reconstrucción es que la acción de Ulate se interpreta como una reacción a un fallido intento por convertirse en candidato presidencial para las elecciones de $1944 .{ }^{23}$ Otilio Ulate quedaría así representado como un individuo con intereses políticos que no dudaría en enfrentar la Reforma Social si eso lo llevaba a la presidencia.

En 1969, en el contexto de una discusión pública acerca de la legalidad de la inscripción del Bloque de Obreros, Campesinos e Intelectuales cuya papeleta lideraba Eduardo Mora Valverde 19 Fallas, Mora y Ferreto, Calderón Guardia, José Figueres y Otilio Ulate a la luz de los últimos acontecimientos políticos, pp. 3-13. La idea de "otro Calderón" es distinta en el título de la entrevista que le hizo Guillermo Villegas a la primera esposa de Calderón Guardia. Para Villegas, militante liberacionista, ese "otro Calderón" es el Calderón que los oposicionistas no conocieron, es decir, un hombre disciplinado, bondadoso, preocupado por el país, etc. Spoelder y Villegas, El otro Calderón Guardia.

20 Manuel Mora, Dos discursos en defensa de Vanguardia Popular. Contestación a don Otilio Ulate y a don José Figueres (S.L., S.E., 1958).

21 Mora, Dos discursos en defensa de Vanguardia Popular, p. 5.

22 Mora, Dos discursos en defensa de Vanguardia Popular, p. 17.

23 Molina, Los pasados de la memoria, capítulos 4 y 13. 
para las elecciones de 1970, Manuel Mora envío una carta a Rafael Ángel Calderón Guardia y otra a José Figueres. El objetivo de esas misivas era realizar una presión sobre los caudillos de los principales partidos en pugna, para que reconocieran la legalidad de la participación del Bloque en esos comicios. Por eso, Manuel Mora intentó utilizar la narración histórica sobre la Guerra Civil para legitimar a su partido, algo que ya había practicado, pero sin éxito, en $1961 .{ }^{24}$ En ese sentido, Mora describe la alianza entre republicanos y comunistas como purificadora para los primeros quienes habrían pasado de ser denunciados como corruptos o malos administradores, a ser acusados por llevar adelante la Reforma Social. El recurso de la memoria, le sirve al líder comunista como una herramienta para enfrentar la ilegalidad. Así, si su partido era sacado de la arena política era justamente porque en el pasado había sido honesto, no había sido revanchista y siempre había actuado por el bien del país. Justo por esa lucha se había ilegalizado al Partido Comunista según lo constataba Mora en su carta a Calderón:

"La guerra civil fue la culminación de la campaña de odios que durante varios años se mantuvo contra usted y contra nosotros. En esa guerra nos corrimos la misma suerte los calderonistas, los comunistas, usted y yo. Terminada la guerra vinieron las represalias y una de esas represalias fue el párrafo segundo del artículo 98 de la Constitución. Como usted lo sabe, esta disposición constitucional se nos ha aplicado con toda saña y para justificar semejante política, reñida con las tradiciones de nuestro pueblo, se han afirmado tres cosas: que nosotros fuimos los instigadores de los 'crímenes de Calderón Guardia', que nosotros somos una amenaza para la soberanía nacional y que nosotros

24 Manuel Mora, "Conozca el pueblo los entretelones de la Guerra Civil de 1948", en ídem, Manuel Mora Valverde. Discursos, 1934-1979 (San José: Editorial Presbere, 1980), pp. 395418. 
somos enemigos del régimen democrático", ${ }^{25}$

Dentro de esta narrativa, los calderonistas tendrían una deuda con el pasado comunista: no solamente habían sido rescatados de un golpe de Estado en 1942, sino que habían sido los comunistas los que sufrieron y fueron perseguidos por los errores políticos cometidos por los calderonistas. De ahí que Mora finalizase argumentando que su dolor venía provocado por el desprecio de sus antiguos colaboradores: "nunca ha dejado de dolernos y de indignarnos que nuestros aliados de ayer sean nuestros verdugos de hoy". ${ }^{26}$ De esa manera, en el discurso de Mora se confirmaba la imagen comunista de un Calderón Guardia que cambiaba su carácter al distanciarse de los vanguardistas.

En 1977, un año antes de unas reñidas elecciones presidenciales, ${ }^{27}$ el periodista Guillermo Villegas Hoffmeister entrevistó al Capitán Mario Fernández Piza, quien había sido el Jefe del Estado Mayor de las fuerzas militares del gobierno durante la Guerra Civil de 1948. Fernández se concentró entonces en recalcar los errores cometidos por los combatientes de Vanguardia Popular. ${ }^{28}$ La reacción a su testimonio de parte de los líderes comunistas Manuel Mora, Arnoldo Ferreto, Eduardo Mora y Fernando Chávez dio como resultado una nueva sistematización testimonial de la versión comunista sobre los orígenes de la guerra civil. ${ }^{29}$

Curiosamente, en esta nueva narrativa, Manuel Mora afirma que, a pesar de que

25 Manuel Mora, 2 cartas de Manuel Mora a Calderón Guardia y José Figueres (Comité Central del Frente de Acción Universitaria, FAU: Imprenta Elena, 1969), pp. 13-14.

26 Mora, 2 cartas de Manuel Mora a Calderón Guardia y José Figueres, p. 14.

27 Eduardo Oconitrillo, Cien años de política costarricense 1902-2002. De Ascensión Esquivel a Abel Pacheco (San José: EUNED, 2004), pp. 215-232.

28 "Tuerto en tierra de ciegos. Testimonio del Capitán don Mario Fernández Piza, Jefe del Estado Mayor de las Fuerzas Militares del Gobierno", Guillermo Villegas Hoffmeister, El gobierno sobre las armas (San José: Editorial de la Universidad de Costa Rica, 2002), pp. 35-60.

29 Villegas Hoffmeister, El gobierno sobre las armas, pp. 193-305. 
las "grandes fuerzas económicas del país... no ocultaban sus intenciones de dar un golpe de estado", su blanco de disgusto no era la Reforma Social, sino "la perspectiva revolucionaria que habíamos logrado abrir". ${ }^{30}$ En ese sentido, la misión que se había impuesto la oposición en la década de 1940 era apoderarse del gobierno para ilegalizar al Partido Comunista y deshacerse del movimiento sindical. De esa forma, Mora trata de exponer la visión de que Vanguardia Popular era la fuerza política detrás de las principales transformaciones y, por tanto, la manera de atacar esas reformas era deshacerse de ese partido. La ilegalización del Partido Comunista, ya superada cuando Mora escribió el texto en mención, seguía siendo presentada como el objetivo central de un movimiento conservador que buscaba frenar la transformación social en Costa Rica. Un año antes, en 1976, Mora incluso sostuvo que la ilegalización política de los comunistas había sido el castigo por haber llevado adelante la Reforma Social. ${ }^{31}$ Por eso, desde esta lectura, los comunistas se habrían convencido de luchar incluso militarmente para "defender la perspectiva revolucionaria de Costa Rica y para defender su propia existencia, seriamente amenazada". ${ }^{32} \mathrm{La}$ Guerra Civil de 1948 fortalecía entonces la constatación de que, efectivamente, era la lucha de clases el motor de las desavenencias políticas de la década de 1940.

Esa perspectiva, lanzada a la arena pública durante varios lustros por los comunistas, alimentó los análisis que sobre los años cuarenta se hicieron en Costa Rica al final de la década de 1970 y en los inicios de la de 1980. Los trabajos que más enfatizan esa tendencia fueron escritos por Manuel Rojas en 1979, por Jorge Mario Salazar en 1981, por Jacobo Schifter ese mismo año y por Gerardo Contreras y José Manuel Cerdas en $1988 .^{33}$ No hay duda de que el

30 "'Ha llegado el momento de hablar claro. Testimonio del licenciado Manuel Mora Valverde", Villegas Hoffmeister, El gobierno sobre las armas, p. 212.

31 Manuel Mora, "Marchamos firmes por el camino que nos trazó el 12 Congreso", en en ídem, Manuel Mora Valverde. Discursos, 1934-1979, p. 692

32 Villegas Hoffmeister, El gobierno sobre las armas, p. 213.

33 Manuel Rojas Bolaños, Lucha Social y Guerra Civil en Costa Rica 1940-1948 (San 
impacto de las memorias comunistas que se habían delineado en las décadas anteriores, había hecho mella en la manera en que los científicos sociales costarricenses analizaban los orígenes del conflicto bélico. ${ }^{34}$

\section{El estallido de la Guerra Civil}

Según el folleto de la CPPVP de 1948, el primer ensayo de “desobediencia civil” lo llevó adelante la oposición en 1947 con la "Huelga de Bancos". El origen de esa huelga, mejor

José: Editorial Porvenir, 1989, originalmente publicado en 1979); Jorge Mario Salazar Mora, Política y reforma en Costa Rica, 1914-1958 (San José: Editorial Porvenir, 1981); Jacobo Schifter, La fase oculta de la Guerra Civil en Costa Rica (San José: EDUCA, 1981) y Gerardo Contreras y José Manuel Cerdas, Los años 40: historia de una política de alianzas (San José, Editorial Porvenir; Instituto Costarricense de Estudios Sociales, 1988). Es interesante que hayan sido dos historiadores extranjeros los primeros en apuntar los límites de esta interpretación: Lowell Gudmundson, "Costa Rica and the 1948 Revolution: Rethinking the Social Democratic Paradigm," en Latin American Research Review, Vol. 19, No. 1. (1984), pp. 235-242 y Fabrice E. Lehoucq, "Class Conflict, Political Crisis and the Breakdown of Democratic Practices in Costa Rica: Reassessing the Origins of the 1948 Civil War," en Journal of Latin American Studies, Vol. 23, No. 1, (Feb., 1991), pp. 37-60. La publicación en español de este texto de Lehoucq en la Revista de Historia (Costa Rica), No. 25 (enero-junio de 1992), pp. 65-96, mereció una ligera crítica de parte de Rodrigo Quesada cuyo trasfondo parece haber sido la defensa de la perspectiva de lucha de clases para el análisis de la década de 1940. Ver: Rodrigo Quesada Monge, "Asalto al paraíso o los "peces dorados en los ojos de Catalina"' en Revista de Historia (Costa Rica), No. 27 (enero-junio de 1993), pp. 149-159, especialmente p. 154. Manuel Solís redimensiona la crítica al trabajo de Lehoucq señalando que dado el cuadro que describen los testimonios que él analiza, "queda la impresión que un énfasis en la racionalidad de los actores, y en particular de los que observa Lehoucq, es unilateral y forzado... La gente tomó sus decisiones con el corazón más que con la cabeza”. Solís, La institucionalidad ajena, p. 267. Para una crítica a la aproximación de Solís al testimonio de Barahona Streber sobre la Reforma Social, ver: Molina, Los pasados de la memoria, capítulos 9 y 14.

34

Ver Molina,

Los pasados de la memoria, capítulo 5. 
conocida en el recuerdo oposicionista como Huelga de Brazos Caídos, ${ }^{35}$ radicaba en la libertad con que los oposicionistas ocupaban puestos dentro de las instituciones del gobierno. Según los comunistas: “El pueblo no se sumó al movimiento y por el contrario, tomó la actitud de apoyar al Gobierno para intentar quebrar la intentona". ${ }^{36}$ De ahí que, continuamente, las memorias comunistas identificarán a este movimiento como una "huelga de patronos", de acuerdo con ellos realizada en contra del pueblo. Empero, el gobierno reaccionaría de forma débil a ese apoyo, firmando un pacto con la oposición en la que le cedía el "aparato electoral". El resultado era esperado: “Asaltó así la oposición el aparato electoral y lo convirtió en un instrumento mediante el cual habría de realizar, como realizó, un gigantesco fraude desde el propio Registro Electoral. Amañó así un triunfo, logrando apenas una ventaja de unos diez mil votos sobre la votación alcanzada por el Dr. Calderón Guardia", ${ }^{37}$

35 Roberto Fernández Durán, La huelga de brazos caídos (San José: Editorial Liberación Nacional, 1953).

36 Comisión Política de Vanguardia Popular, Los Sucesos de Costa Rica, p. 15.

37 Comisión Política de Vanguardia Popular, Los Sucesos de Costa Rica, p. 15. La memoria del resultado de las elecciones se constituyó en uno de los ejes de los recuerdos del líder comunista Jaime Cerdas. De acuerdo con Cerdas, él fue quien descubrió el fraude que había ocurrido en los comicios pero por pura casualidad: “Con motivo de existir grandes sospechas de la actuación del Director del Registro Electoral, el Congreso me nombró su delegado ante el Registro y ante el Tribunal de Elecciones. Una noche, estando en el desempeño de esas funciones, quise darle una broma a uno de los fiscales del Partido Unión Nacional, que además de colega, era amigo personal y le saqué de la bolsa una Tribuna pensando devolvérsela luego, cosa que olvidé. Al día siguiente, encontré en dicha Tribuna que la lista de adhesiones calderonistas estaban parcialmente marcadas. En el Registro comprobé que todos los electores marcados habían sufrido traslado. Inmediatamente comuniqué el hallazgo al Partido y este comisionó a los licenciados Carballo Corrales y Osvaldo Rodríguez, quienes pudieron comprobar en el Registro, de manera fehaciente, la magnitud del fraude descubierto". Jaime Cerdas, “Anulación de las elecciones del 48”, en La Nación, 12 de junio de 1988, foro dominical. Cuando Cerdas dice Tribuna, se refiere a un ejemplar del periódico La Tribuna. Ver: Jaime Cerdas, La otra vanguardia. Memorias (San José: EUNED, 1993), pp. 156-157. La tesis de que en las elecciones del 8 de febrero de 1948 había ocurrido un fraude electoral basado en la alteración del padrón electoral fue defendida por los comunistas a finales de ese mes: "Vanguardia en defensa de nuestra constitución. Manuel 
De acuerdo con el folleto de la CPPVP de 1948, la oposición estaba dividida en dos filas frente a la anulación de la elección presidencial de Ulate: "una se pronunciaba por la guerra civil; la otra por un acuerdo transaccional mediante el cual surgiera un tercero al ejercicio del Poder Ejecutivo, representando los círculos más poderosos de la banca, el comercio y la agricultura", ${ }^{38}$ El primer grupo, "más agresivo”, estaba constituido por "falangistas, pronazis y súbditos del Eje que habían figurado en las Listas Negras” y “estaba ya en camino de la insurrección, cualquiera que fuera el resultado electoral, si éste no favorecía sus pretensiones". ${ }^{39}$ Los comunistas sostienen que su partido quedó fuera de todas las conversaciones, ya que ellos no aceptarían una transacción que "se hiciera dándole la espalda a los intereses del pueblo". ${ }^{40}$ En este clima, cuando la transacción "parecía ya hecha”, ocurrió lo que se temía: "José Figueres se alzó en sus latifundios del Sur del país, en conexión con la Legión Caribe". ${ }^{41}$

En la versión escrita por Fallas, Mora y Ferreto en 1955, el énfasis en la división de los grupos de cara al resultado de las elecciones es distinto. En lugar de prestar atención a la oposición, los líderes comunistas se concentran en las divergencias existentes entre los grupos oficialistas. De esta manera, al darse el resultado electoral que favorecía a Ulate, "se planteó para los partidos Republicano Nacional (calderonista) y Vanguardia Popular la siguiente alternativa: aceptar bajo ciertas condiciones el resultado electoral, o anular por fraudulentas esas elecciones y encarar entonces el peligro de la guerra civil, que era inminente". ${ }^{42}$ Aquí ocurre otro giro en la narrativa comunista al incluirse la imagen de un Otilio Ulate preocupado por una transacción que Mora y Luis Carballo definen categóricamente la actitud de Vanguardia Popular en estos difíciles momentos", Trabajo, 21 de febrero de 1948, pp. 1-2 y 6-7.

38 Comisión Política de Vanguardia Popular, Los Sucesos de Costa Rica, p. 16.

39 Comisión Política de Vanguardia Popular, Los Sucesos de Costa Rica, p. 16.

40 Comisión Política de Vanguardia Popular, Los Sucesos de Costa Rica, p. 16.

41 Comisión Política de Vanguardia Popular, Los Sucesos de Costa Rica, p. 16.

42 Fallas, Mora y Ferreto, Calderón Guardia, José Figueres y Otilio Ulate a la luz de los últimos acontecimientos politicos, p. 3. 
permitiera la formación de un gabinete, “que garantizara a los partidos perdidosos contra posibles persecuciones, a reconocer la deuda política de los dos partidos y a mantener las leyes sociales"; una propuesta que los comunistas encontraron "aceptable", pero no así Calderón quien "se negó a entrar siquiera en negociaciones sobre las bases propuestas". Esta posición, que insiste en un Calderón empecinado en ganar las elecciones a su gusto, se combina con la ceguera de parte de la Dirección de Vanguardia Popular que se habría dejado arrastrar "por la justa indignación de las masas populares". ${ }^{43}$ Así, hacia 1955 ya están fortificadas dos visiones sobre el estallido de la guerra: una que pone el acento en el fraude electoral como justificación suficiente para anular las elecciones y otra que muestra divididos a los grupos oficialistas frente a un actor, Otilio Ulate, con el que había sido posible una transacción. Sin duda, los intentos de invasión calderonistas de diciembre de 1948 y 1955 jugaron un papel central en la evolución de esas narrativas.

El movimiento de Figueres, según los comunistas en su folleto de 1948, se habría beneficiado de las intrigas, el desorden y el oportunismo que reinaban en el Gobierno, siendo una de las más importantes la negación del Ministro de Seguridad Pública René Picado en darle armas al "pueblo". Por eso, para los comunistas René Picado era en realidad "no sólo un instrumento del Embajador yanqui, sino un mercader muy peligroso". ${ }^{44}$ En contraste, Figueres hacía la guerra con "oficiales y soldados experimentados y abundantes y buenas armas y municiones". ${ }^{45} \mathrm{El}$ embajador estadounidense, enseguida apoyó a los insurrectos utilizando "la red de emisoras que la Public Road Administration" tenía establecidas en todo el país para "dar información" y 43 Fallas, Mora y Ferreto, Calderón Guardia, José Figueres y Otilio Ulate a la luz de los últimos acontecimientos políticos, p. 3. La imagen de la "ceguera" ya se encuentra en el informe al Sétimo Congreso del Partido Vanguardia Popular, que presentó Arnoldo Ferreto en 1950. Arnoldo Ferreto, "Informe sobre la situación política nacional; antecedentes y perspectivas", en, ídem, Vida Militante (San José: Editorial Presbere, 1984), pp. 113-158, especialmente p. 124.

44 Comisión Política de Vanguardia Popular, Los Sucesos de Costa Rica, p. 17. Según los comunistas, René Picado le había vendido las mejores armas del Gobierno a Somoza.

45 Comisión Política de Vanguardia Popular, Los Sucesos de Costa Rica, p. 17. 
"difundir las órdenes para los rebeldes". Asimismo, un "técnico americano en sabotaje" era el encargado de dirigir los actos de dinamitación mientras que el Embajador estadounidense ejercía presión contra el gobierno. ${ }^{46}$

Esta narrativa que liga a René Picado con la embajada estadounidense tenderá a consolidarse en los siguientes años. ${ }^{47}$ En el análisis de Fallas, Mora y Ferreto de 1955, Picado ya es presentado no solo como un "hombre de confianza de la Embajada Americana", sino también como cercano a Somoza. No hay además una distinción en estas narrativas cuando se refieren a la representación diplomática estadounidense: para las vanguardistas, la embajada estadounidense estuvo siempre en su contra y a favor de los grupos que intentaban sacarlos del poder y marginarlos políticamente. ${ }^{48}$ Junto a la embajada estadounidense y René Picado, los $46 \quad$ Comisión Política de Vanguardia Popular, Los Sucesos de Costa Rica, p. 18.

47 Aunque la relación entre el Ministerio de Seguridad Pública y la representación diplomática estadounidense en Costa Rica solía ser muy estrecha, René Picado parece haber rebasado los límites de esa relación de forma tal que se convirtió, a fuerza, en sospechoso para los líderes comunistas. La sospecha, por tanto, no era infundada. En noviembre de 1944 el Encargado de Asuntos ad interim S. Walter Washington envío un memorándum al Secretario de Estado norteamericano en el que le detallaba una conversación con René Picado. Según el informe, Picado le había aconsejado a su hermano, el presidente, realizar un viaje fuera del país en 1945 dejándolo a él en su lugar (René era el segundo designado a la presidencia) "por un tiempo suficiente que le permitiera a él tomar la acción drástica que es necesaria para deshacerse de la influencia comunista en el Gobierno". United States National Archives. Decimal Files, 818.00B/112344 (November 23, 1944), p.2. La actitud de René Picado no era nueva. El 1 de mayo de 1944 le envío una carta al Encargado de Negocios de Estados Unidos en San José diciéndole que él era anticomunista y que no estaba dispuesto a tolerar la intromisión de los comunistas en los cuarteles ni "el aumento del comunismo en Costa Rica". Picado dice más en esa misiva: "Si mañana para mantener mi anterior determinación tuviera que privar de su vida, o su libertad, a mi hermano el Presidente Electo, al Primer designado Electo Francisco Calderón Guardia, y al Jefe Comunista Manuel Mora, estoy dispuesto a hacerlo, y a asumir la Presidencia de República en mi carácter de Segundo designado", USNADF, 818.00/2040, p. 2. Agradezco la copia de estos documentos al profesor Iván Molina.

48 Esto contrasta con la relativa buena impresión que hacia el final de la década de 1940 tenían los representantes diplomáticos norteamericanos acerca de Manuel Mora y su partido. Ver: Iván Molina, Anticomunismo reformista. Competencia electoral y cuestión social en Costa 
"militares gobiernistas" aparecen constantemente como saboteadores de las ofensivas lideradas por los vanguardistas. ${ }^{49}$ Frente a ellos, el presidente Picado es representado en 1955 como un hombre débil y complaciente. ${ }^{50}$ Hacia 1958, Manuel Mora matiza esa imagen al intentar presentarlo como "un ilustrado profesor de Historia" a quien lo acongojaba mantener el orden público, por lo que siempre fue temeroso de utilizar la fuerza para hacerlo. ${ }^{51}$ Empero, en 1977 Manuel Mora cataloga a Picado como un gobernante débil que "carecía de la capacidad de decisión para mantener el principio de autoridad en un periodo de conmoción social" y como un presidente que "vivía haciendo equilibrio entre las presiones de la embajada yanqui y de su hermano, y su conciencia que lo empujaba a hacerle honor a los compromisos adquiridos con nosotros" ${ }^{52}$ En suma, las memorias vanguardistas ubican su posición hacia 1948 como difícil: enfrentados militarmente a los grupos conservadores que querían dar al traste con la Reforma Social, a la embajada estadounidense, al Ministro de Seguridad que emprendía el sabotaje en su contra y un presidente Picado que caminaba por la cuerda floja entre la ética y la traición.

\section{La traición republicana}

En la narrativa comunista sobre la Guerra Civil de 1948, juega un papel muy importante la posible traición que el Partido Republicano Nacional desarrolló en contra de los vanguardistas en el fragor de la lucha. Esta es la manera en que el folleto escrito por la CPPVP en 1948 narra

Rica (1931-1948) (San José: Editorial Costa Rica, 2007), pp. 85-96 y 173-190.

49 Fallas, Mora y Ferreto, Calderón Guardia, José Figueres y Otilio Ulate a la luz de los últimos acontecimientos políticos, p. 5

50 Fallas, Mora y Ferreto, Calderón Guardia, José Figueres y Otilio Ulate a la luz de los últimos acontecimientos políticos, p. 6.

51 Mora, Dos discursos en defensa de Vanguardia Popular, p. 54.

52 Villegas Hoffmeister, El gobierno sobre las armas, p. 214. 
ese acontecimiento:

"El General Somoza pidió un buen día al Presidente Picado que fuera a Managua para tratar todo lo relacionado con el apoyo a su Gobierno. Un avión expreso se encargó de llevar a nuestro Presidente a la capital nicaragüense, en donde Somoza y el Encargado de Negocios de los Estados Unidos le esperaban para celebrar una entrevista.

Se le tenía ya redactada una carta que, según el mandatario nicaragüense y el personero yanqui, habría de firmar nuestro Presidente, en la cual pedía 'auxilio contra Figueres y el comunismo'.

Firmada esa carta, el Gobierno de Picado debía dejar acercarse a los Figueristas, abandonar la ciudad capital, dejándola calculadamente en manos de los voluntarios de Vanguardia Popular, e irse a establecer en Liberia, pequeña ciudad cercana a la frontera norte, y la Guardia Nacional — como instrumento americano— se encargaría de lo demás.

... El Presidente Picado se negó a firmar la carta y se volvió a la capital costarricense sin armas pero ya con la amenaza de que la Guardia Nacional de Nicaragua entraría en cualquier momento en que Nicaragua se considerara amenazada por 'Figueres y por los comunistas'.

...No obstante la actitud del Presidente, el alto mando de las fuerzas del Gobierno comenzó a actuar de modo que los acontecimientos nos llevaran a la posición buscada por Somoza.

La protección de Figueres llega entones hasta el grado de que consigue aviones en la Zona del Canal de Panamá. 
A partir de este momento el Presidente Picado está convencido de que la guerra tiene que perderse y que, por lo tanto, "nada hay que hacer"'. ${ }^{53}$

La narración de esta traición se consolidará en los siguientes testimonios y análisis de la guerra hechos por los comunistas. En esencia, el cuadro descrito será el mismo, pero se le agregará nueva información, al tiempo en que otros detalles cambiarán abruptamente. En ese sentido, la traición republicana cambiará de lugar y tiempo y hasta aparecerá como una tentación somocistas más de una vez. En 1955 Mora, Fallas y Ferreto sostenían que Somoza le había negado armas para defenderse al gobierno de Picado, con la intención de que éste debiera recurrir a la Guardia Nacional para enfrentar a Figueres. Así, de acuerdo con esta narración, Somoza ya tenía preparado su plan de intervención en Costa Rica, pero lo habría pospuesto hasta que el gobierno de Picado estuviera tan desesperado como para aceptarlo. La carta que autoriza el movimiento de la Guardia Nacional sobre Costa Rica aparece en el folleto de 1955 como un documento que debía firmar no Picado sino el embajador de Costa Rica en Nicaragua y hasta se afirma por primera vez que Manuel Mora conoció esa misiva. ${ }^{54}$

El folleto de 1955 también plantea la idea de que la oferta de Somoza fue secretamente aceptada por los militares gobiernistas, quienes, apenas conocieron el plan, se empeñaron en permitirle a Figueres su acercamiento a San José. ${ }^{55}$ En este punto es en donde cambia la narración sobre la traición. En el fragor de las negociaciones en la embajada de México —afirman Mora, Ferreto y Fallas en 1955-Calderón Guardia había llamado a los comunistas 53 Comisión Política de Vanguardia Popular, Los Sucesos de Costa Rica, pp. 18-19. Las cursivas son del original.

54 Fallas, Mora y Ferreto, Calderón Guardia, José Figueres y Otilio Ulate a la luz de los últimos acontecimientos políticos, p. 6-7.

55 Fallas, Mora y Ferreto, Calderón Guardia, José Figueres y Otilio Ulate a la luz de los últimos acontecimientos políticos, p. 7. 
para dejarles saber que "poseía una 'nueva' fórmula de triunfo ofrecida por Somoza: el gobierno se trasladaría a Liberia, y la Guardia Nacional Nicaragüense entraría a Costa Rica para derrotar a Figueres". ${ }^{56}$ Según esta versión, Picado no habría viajado hasta Nicaragua sino que este plan le fue presentado en Puntarenas al presidente, a Calderón y a Manuel Mora por un mensajero de Somoza. El jefe de la Guardia Nacional habría alegado entonces que sólo necesitaba una carta firmada por Picado pidiendo el auxilio nicaragüense para movilizarse; una propuesta que fue rechazada por todos los allí presentes. No obstante, a esta nueva reunión la narrativa comunista en 1955 agrega una traición diferente: "Manuel Mora se pronunció contra esa proposición y en nombre de Vanguardia Popular le pidió al Presidente rechazarla. Picado estuvo de acuerdo con el criterio de nuestro compañero, y así se dio por terminada la entrevista, regresando Manuel Mora solo e inmediatamente a San José para seguir interviniendo en las conversaciones de la Embajada de México. Picado y Calderón Guardia se quedaron unas horas más en Puntarenas, y entonces el Presidente cambió de criterio y sobre el ala del propio avión nicaragüense firmó el documento que Somoza necesitaba para intervenir". ${ }^{57}$ De acuerdo con esta versión, tanto Picado como Calderón habrían traicionado a los comunistas a sus espaldas justo después de haberles jurado su fidelidad. ${ }^{58}$

En 1977 Manuel Mora agrega nuevos elementos a esta cita, cambiando un tanto su narrativa. Mora dice que mientras él se encontraba en la Embajada de México, recibió la noticia de que Calderón y Picado habían ordenado la preparación de un avión para viajar a Puntarenas, pero los milicianos vanguardistas que estaban en el aeropuerto impidieron que el artefacto $56 \quad$ Fallas, Mora y Ferreto, Calderón Guardia, José Figueres y Otilio Ulate a la luz de los últimos acontecimientos políticos, p. 9.

57 Fallas, Mora y Ferreto, Calderón Guardia, José Figueres y Otilio Ulate a la luz de los últimos acontecimientos políticos, p. 10.

58 Fallas, Mora y Ferreto, Calderón Guardia, José Figueres y Otilio Ulate a la luz de los últimos acontecimientos políticos, p. 14. 
despegara. ${ }^{59}$ En esta visión, que tiende a seguir afirmando el poder de los comunistas sobre la movilización de personas en la capital —incluyendo a altos jerarcas políticos— ${ }^{60}$, Picado habría tenido que buscar a Mora para convencerlo de que su intención no era abandonar el país sino ir a Puntarenas a dialogar con "una persona que había salido en busca de armas". Así, Picado aparece como un presidente sin poder para decidir acerca de lo que se movilizaba desde la capital, por lo cual tiene que invitar al líder comunista a que lo acompañara. ${ }^{61} \mathrm{~A}$ la vez, Mora identifica por primera vez al "mensajero de Somoza":

“Nuestro avión aterrizó en La Chacarita, donde nos esperaban las autoridades del lugar. Allí me explicó el doctor Calderón Guardia que el avión que esperaban venía de Nicaragua y que la persona que llegaría en ese avión era don Francisco Calderón Guardia. Efectivamente, un rato después llegó el avión que esperaban. Era un bombardero del ejército nicaragüense... Se abrió la portezuela y bajó don Francisco quien se sorprendió, de encontrarme a mí junto con el doctor Calderón Guardia y don Teodoro Picado esperándolo. Sin mucho preámbulo, don Francisco informó sobre el resultado de su gestión.

59 Arnoldo Ferreto no relata este incidente a pesar de que en 1977 afirmó que él mandaba la tropa que resguardaba el aeropuerto. "Los comunistas pusimos los muertos. Testimonio del profesor don Arnoldo Ferreto Segura, Jefe del Estado Mayor del Partido Comunista Vanguardia Popular durante la Guerra Civil de 1948", Villegas Hoffmeister, El gobierno sobre las armas, p. 206.

60 Este punto, recreado por la narrativa comunista constantemente, convenció al historiador John Patrick Bell, Guerra civil en Costa Rica. Los sucesos políticos de 1948 (San José: Editorial Universitaria Centroamericana, cuarta edición, 1986), p. 192. En una entrevista concedida en 1982, Ferreto insiste en que quienes mandaban en la capital eran las fuerzas comunistas. Gerardo Contreras, "Entrevista al Prof. Arnoldo Ferreto, dirigente del Partido Vanguardia Popular. Tema: campaña electoral de 1948 y guerra civil", 14 de diciembre de 1982, p. 18. Agradezco enormemente al profesor Contreras el haberme facilitado una copia de este documento.

61 Villegas Hoffmeister, El gobierno sobre las armas, p. 234. 
El presidente Somoza ofrecía mil hombres armados para que el gobierno derrocara a Figueres. Pero al mismo tiempo exigía que el presidente Picado le solicitara su ayuda, por medio de una carta". ${ }^{62}$

Mora indica entonces que él exigió saber si lo que se ofrecía era la intervención de la Guardia Nacional nicaragüense y que, en ese caso, los comunistas se oponían completamente a ese tipo de ayuda por considerarla una ofensa a la patria. Rafael Ángel Calderón, según Mora, concordó con esa postura y Picado rechazó la oferta de Somoza dando por terminadas las negociaciones. Pero Mora agrega, otra vez, un nuevo episodio a su memoria de esta reunión:

"Don Francisco me pidió que nos apartáramos un poco del grupo, y así lo hicimos. Comenzó diciéndome que él no podía ser desleal con nosotros; que él estaba cogido en un engranaje del que le era muy difícil liberarse pero que él consideraba que era su deber informarnos que el plan de Somoza no se orientaba pura y simplemente a aplastar a Figueres sino que también había el propósito de aplastarnos a nosotros los comunistas. Como yo le preguntara que cómo podía explicarse que don Teodoro estuviera buscando ayuda militar en Nicaragua, horas después de haber capitulado, don Francisco me explicó que era Somoza el que estaba más preocupado con la capitulación de Picado porque consideraba a Figueres un peligro muy serio para Nicaragua". ${ }^{63}$

En esta versión, Mora presenta su intervención en esta reunión como fortuita y le da el papel central de la narración a Francisco Calderón Guardia. Es el mismo Francisco quien le habría

62 Villegas Hoffmeister, El gobierno sobre las armas, p. 234-235.

63 Villegas Hoffmeister, El gobierno sobre las armas, pp. 235-236. 
revelado al líder comunista el plan somocista: trasladar al gobierno de San José a Liberia, dejar la capital bajo el control de los comunistas, facilitar la entrada de Figueres a San José y luego pedir la ayuda de Somoza para combatir a los alzados y a los vanguardistas. Y sería el mismo Francisco Calderón quien le habría dicho a Mora que en "su criterio íntimo" era "preferible llegar a una transacción con Figueres que permitir que Costa Rica fuera invadida por la Guardia Nacional de Nicaragua". ${ }^{64}$ En otras palabras, Francisco Calderón le habría sugerido a Mora el llegar a un arreglo con Figueres. Así, de allí Mora salió en avión para San José amparado en la idea de que el trato con Somoza estaba roto, pero, según él, después de que se alejó, "el señor Picado cambió de criterio y sobre el ala del avión nicaragüense escribió la carta que Somoza le solicitaba". ${ }^{65}$

Una de las cosas más llamativas en esta narrativa de la traición republicana y la complicidad somocista, es que los representantes estadounidenses, tanto en Nicaragua como en Costa Rica, son catalogados por los comunistas como los propulsores de la maniobra. El primero en descartar esta participación en el sentido en que la presentó el testimonio vanguardista, fue el investigador Jacobo Schifter. En un primer trabajo publicado en 1982, Schifter, analizando los documentos confidenciales del Departamento de Estado, identificó efectivamente un interés de los norteamericanos por deshacer la relación entre los comunistas y los republicanos para parar así la influencia de los izquierdistas en el gobierno. No obstante, el costo de ese proyecto no involucraba para los representantes norteamericanos una capitulación o derrota militar del gobierno de Picado. ${ }^{66}$ Cuatro años después, este investigador probó que al invadir Costa Rica, Somoza había actuado por su cuenta y a contrapelo de lo que le exigía el representante de negocios

64 Villegas Hoffmeister, El gobierno sobre las armas, p. 236.

$65 \quad$ Villegas Hoffmeister, El gobierno sobre las armas, p. 237.

66 Jacobo Shifter Sikora, Costa Rica 1948: Análisis de los documentos confidenciales del Departamento de Estado (San José: EDUCA, 1982), pp. 175-201, especialmente p. 180. 
del Departamento de Estado. De hecho, Somoza tuvo que parar su "ayuda" al gobierno de Picado por exigencias venidas desde los Estados Unidos. ${ }^{67}$

Más recientemente, Marcia Olander ha dado nuevas luces sobre la cooperación entre Somoza y el gobierno de Picado durante la Guerra Civil. De acuerdo con Olander, en su camino de México a Costa Rica, René Picado hizo una escala en Nicaragua el 15 de marzo de 1948, de donde se trasladó a San José con al menos 35 ex guardias nacionales. ${ }^{68}$ Empero, una de las más importantes revelaciones del trabajo de Olander es que, a pesar de que Somoza le comunicó al Departamento de Estado que no enviaría más tropas a Costa Rica en respeto de la orden venida desde Washington (como lo indica Schifter), lo que realmente pasó es que el presidente Picado rechazó el 22 de marzo la oferta de hombres que le hizo Somoza para pelear contra los alzados. No obstante, el 16 de abril Francisco Calderón, autorizado por Picado, firmó un acuerdo con Somoza para que éste defendiera la frontera en caso de sentirse amenazado. Somoza lo hizo y eso precipitó la firma de los acuerdos de paz. El 17 de abril, según Olander, Manuel Mora le habría declarado al Cuerpo Diplomático que los responsables de la invasión somocista habían sido los hermanos Calderón Guardia. ${ }^{69}$ Estos datos permiten pensar que Mora tuvo que acomodar

67 Jacobo Schifter, Las alianzas conflictivas. Las relaciones de Estados Unidos y Costa Rica desde la Segunda Guerra Mundial a la Guerra Fría (San José: Asociación Libro Libre, 1986), pp. 267-273.

68 En un testimonio dado en la década de 1990, el líder comunista Álvaro Montero Vega destaca la presencia de un "coronel nicaragüense, de apellido Fonseca, que jefeaba un grupo de sus compatriotas". De acuerdo con Montero Vega, él se enteró después que "Fonseca había sido expulsado de la Guardia Nacional. Somoza le había dicho que fuera a Costa Rica para ver si se ganaba el derecho de volver a pertenecer a su Guardia”. Dicho testimonio podría explicar un poco la manera en que Somoza seleccionó a la gente que envío con Picado. Ver: Nicolás Pérez Delgado, Volando Bala 1948 (San José: Composiciones Culturales Macondo S.A., 1998), p. 191

69 Marcia K. Olander, "Central American Foreign Policies and the Costa Rican Civil War of 1948: Picado, Somoza and the Desperate Alliance” (Ph.D. Dissertation, University of Kansas, 1999), pp. 237-241. También ver Schifter, Las alianzas conflictivas, pp. 278-283. 
su testimonio posteriormente, de forma tal que la traición apareciera como una maquinación estadounidense a la cual se alinearon los republicanos en un intento desesperado por sobrevivir a su hecatombe. La actitud de Mora en ese sentido, estaría a tono con la idea partidista de que su suerte política fue decidida por el Departamento de Estado; una acusación que políticamente no afectaba directamente a los grupos que se mantuvieron en el poder después de 1948, quienes eran a su vez los mismos grupos en los que descansó la decisión de legalizar al Partido Comunista.

\section{La capitulación}

Según el folleto de la CPPVP publicado en 1948, la capitulación del gobierno de Picado se dio a espaldas del calderonismo y el comunismo y se arregló pidiendo "garantías de vidas $y$ haciendas para los que habian sido amigos del Gobierno". ${ }^{70}$ De acuerdo con esta narrativa, Manuel Mora fue entonces llamado a la embajada mexicana y allí se enteró de la capitulación y de que la guerra era expuesta internacionalmente como un conflicto liderado por los comunistas en armas. En ese contexto, la amenaza de una invasión somocista se volvió más aguda lo cual, de acuerdo a este folleto, convenció a Mora de la necesidad de un arreglo. Así se expone este episodio:

"No le quedó otro camino — informó luego el compañero Mora- que aprovecharse de la circunstancia de que la mayoría de los soldados de la fila eran vanguardistas para tratar de reabrir negociaciones con el Cuerpo Diplomático, dirigidas a asegurarle algunas garantías a la clase trabajadora; y actuó inmediatamente en la línea de sacar el mejor

$70 \quad$ Comisión Política de Vanguardia Popular, Los Sucesos de Costa Rica, p.20. La cursiva es del original. 
partido posible de una derrota que no estábamos ya en capacidad de impedir, porque era obra evidente del Departamento de Estado" ${ }^{71}$

Inmediatamente, se adjunta a este documento una carta de Teodoro Picado dirigida a Manuel Mora y a Calderón Guardia en la que el presidente explica que su renuncia a continuar con la guerra se debía a "fuerzas incontrastables" y a un posible "vejamen" al que el país sería sometido si el conflicto continuaba unos días más. ${ }^{72}$ Aunque la carta está fechada el $1^{\circ}$ de abril de 1948, los comunistas no indican qué día habría Manuel Mora recibido la misiva. En 1955, Ferreto, Fallas y Mora anotan que las "fuerzas incontrastables" provenían de una amenaza de invasión al país, hecha por el Secretario de Estado norteamericano, quien se habría comunicado con Picado para hacerle saber su preocupación por la actividad comunista en Costa Rica. ${ }^{73}$

Hacia 1958 Manuel Mora recuerda esos hechos asegurando que los comunistas tuvieron que aceptar la capitulación de Picado para evitar una invasión al país de "ejércitos de otros países".${ }^{74}$ En cambio, en 1977 Mora cambia el orden de los sucesos relatados de forma que Picado ya había capitulado para el momento de la reunión en Puntarenas, en la que se le comunicó el trato con Somoza. En este orden Picado no podría haber renunciado cuando se enteró de la invasión de "fuerzas incontrastables" al país, una revelación que se habría hecho entre el 17 y el 19 de abril, por lo que Mora sustituye en su narrativa a Picado por el embajador mexicano, quien aparece como aquel que dio a conocer la noticia de la invasión somocista y de la posible movilización de marines estadounidenses por la zona sur. ${ }^{75} \mathrm{~A}$ su vez, el líder comunista también indica que 71 Comisión Política de Vanguardia Popular, Los Sucesos de Costa Rica, p. 20.

72 Comisión Política de Vanguardia Popular, Los Sucesos de Costa Rica, pp. 20-21.

73 Fallas, Mora y Ferreto, Calderón Guardia, José Figueres y Otilio Ulate a la luz de los últimos acontecimientos políticos, p. 8.

$74 \quad$ Mora, Dos discursos en defensa de Vanguardia Popular, p. 26.

75 En una conversación con Manuel Mora, que su compañera Addy Salas ubica en México 
el embajador estadounidense Nathaniel Davies, le habría asegurado que la Guardia Nacional nicaragüense abandonaría el país inmediatamente si los comunistas deponían las armas, algo a lo que él respondió con una condición: otorgarle garantías a su partido. ${ }^{76}$

La evidencia disponible muestra que Picado solamente capituló oficialmente el 19 de abril de 1948, al firmar el conocido Pacto de la Embajada de México. El testimonio del mismo Picado es esclarecedor al respecto. De acuerdo con lo apuntado allí, el 13 de abril de 1948 Picado recibió una carta firmada por Figueres y dos de sus principales seguidores en la que le exigían una rendición incondicional y su nombramiento como designados a la presidencia. Picado indica que ese mismo día, él contestó negativamente a esa carta, especialmente porque se negaba a dejar en manos de los rebeldes el poder de forma incondicional. Empero, este contacto permitió la iniciación de las conversaciones en la Embajada de México que finalmente llevarían a la negociación de la paz. ${ }^{77}$

No está claro si la carta de Picado a Calderón y Mora, reproducida en el folleto de la CPPVP de 1948, haya sido alterada en su fecha por los comunistas con alguna intencionalidad o si se trató solo de un error tipográfico. Lo cierto es que al rescatarla en su denuncia del

pocos meses después de la Guerra Civil de 1948, Mora indica que el 17 de abril de 1948 Teodoro Picado lo invitó a ir a Sixaola en avión para que viera con sus "propios ojos la movilización de fuerzas propias de Estados Unidos que estaban listas para invadirnos y 'pacificarnos'... Teodoro quería que yo lo acompañara, y viera con mis propios ojos la movilización, en Sixaola, de las tropas de los Estados Unidos, listos para invadirnos, pero yo no necesitaba ir para creerle". Ver: Addy Salas, Con Manuel. "Devolver al pueblo su fuerza" (San José: Editorial de la Universidad de Costa Rica, 1997), pp. 162-163. Esta información no fue revelada por Mora en sus otras narrativas públicas sobre la capitulación de Picado. Al respecto, este dato vuelve a cambiar lo apuntado por Mora en sus otros testimonios, en donde solo señala haber recibido la carta de Picado, o bien haber escuchado la noticia de que los marines invadirían Costa Rica de la boca del embajador mexicano.

$76 \quad$ Villegas Hoffmeister, El gobierno sobre las armas, p. 239.

77 Teodoro Picado, El pacto de la Embajada de México. Su incumplimiento (Managua: Editorial Centroamericana, 1950), pp. 12-13. 
incumplimiento del Pacto de la Embajada de México, Picado la reproduce como escrita el 18 de abril de 1948 y no el $1^{\circ}$ de abril como aseguraba la CPPVP. La fecha proporcionada por el presidente que capitulaba está más a tono con el proceso de las negociaciones y con la sentencia de que "fuerzas incontrastables" eran las que lo obligaban a renunciar. ${ }^{78}$ Justamente, la referencia a dichas fuerzas se constituyó en uno de los misterios ligados a la capitulación. Los testimonios comunistas, como se indica arriba, tendieron a interpretar la presión del Departamento de Estado, como la fuerza oculta detrás de la frase de Picado. Al hacerlo así, el rompecabezas vanguardista que apuntaba hacia una conspiración venida desde Washington adquiría mejor forma.

El primer estudio historiográfico sobre la Guerra Civil de 1948 descartó la explicación comunista. En ese sentido, para Oscar Aguilar Bulgarelli las fuerzas a que hacía alusión Picado podían referirse a "una fuerte invasión proveniente de Guatemala que ayudara a Figueres y a los emigrados de los países del Caribe... motivado esto por la invasión de Nicaragua a favor del Gobierno" ${ }^{79}$ El desprecio por la versión vanguardista de parte de Aguilar (algo que repetirá con respecto al Pacto de Ochomogo), no fue asumido por otros estudiosos del tema. Al respecto, al analizar la Guerra Civil casi en perpendicularidad con el esfuerzo de Aguilar, el investigador estadounidense John Patrick Bell confió en el testimonio caldero-comunista para asegurar que la capitulación de Picado se había dado como respuesta a la invasión somocista del noroeste del país y a la posibilidad de un movimiento de marines desde el sur. ${ }^{80}$ Lo mismo asumieron como real los historiadores Gerardo Contreras, José Manuel Cerdas, Jorge Mario Salazar y el sociólogo Manuel Rojas, entre otros. ${ }^{81}$ Incluso los investigadores que han inspeccionado los $78 \quad$ Picado, El pacto de la Embajada de México, pp. 5-6.

79 Oscar Aguilar Bulgarelli, Costa Rica y sus hechos políticos de 1948. Problemática de una década (San José: Editorial Costa Rica, tercera edición 1978), p. 386. Este estudio fue originalmente defendido como tesis de Licenciatura en Historia en 1968.

80 Bell, Guerra civil en Costa Rica, pp. 199-200.

81 Contreras y José Manuel Cerdas, Los años 40: historia de una política de alianzas, p. 
documentos confidenciales del Departamento de Estado, al dejar sin resolver la cuestión de la invasión de marines, han planteado que esa posibilidad no se puede descartar. ${ }^{82}$ Lo cierto del caso es que junto al ambiguo testimonio de Teodoro Picado, fue una afirmación hecha por el historiador Ricardo Fernández Guardia en un libro de historia para escolares y colegiales, la que le proporcionó el peso suficiente al testimonio comunista sobre la invasión de marines, para ser aceptado como un hecho real. ${ }^{83}$

\section{El Pacto de Ochomogo}

La manera en que el folleto de la CPPVP de 1948 se refiere a la actuación de Manuel Mora en las negociaciones conducentes a finalizar el conflicto bélico, lo exponen retrasando los acuerdos hasta "lograr algunas garantías a favor de la clase trabajadora". Según esta narrativa, el Embajador estadounidense estaba disconforme con los atrasos y por eso habría pedido la invasión del país por parte de la Guardia Nacional nicaragüense. Este acontecimiento, "hizo cambiar inmediatamente la posición de Vanguardia Popular; nuestras gentes estaban dispuestas a cualquier sacrificio para evitarle al país la humillación y las consecuencias funestas que habría 160; Jorge Mario Salazar, Crisis liberal y Estado Reformista. Análisis político-electoral 19141949 (San José: Editorial de la Universidad de Costa Rica, 1995), p. 269, Rojas Bolaños, Lucha Social y Guerra Civil en Costa Rica 1940-1948, p. 137.

82 Schifter, Las alianzas conflictivas, pp. 282-283; Longley, "Peaceful Costa Rica, the First Batleground: the United States and the Costa Rican Revolution of 1948", p. 172.

83 Así, tanto los comunistas como algunos de los investigadores mencionados, basan la evidencia sobre la amenaza de una invasión de marines en: Ricardo Fernández Guardia, Cartilla histórica de Costa Rica (San José: Editorial Lehmann, 49 edición, 1976), p. 163. Fernández Guardia asegura que: "Se disponía el Gobierno a resistir en sus cuarteles de San José, cuando fue informado que en la zona del Canal de Panamá se aprestaba una fuerza del ejército americano con carácter de policía, a ser transportada al aeropuerto La Sabana para ponerle fin a las hostilidades, ya que se tildaba de comunistas al numeroso grupo de combatientes militantes del Vanguardia Popular". 
de traerle la intervención de la Guardia Nacional en los asuntos internos de Costa Rica" ${ }^{84}$ Con base en esta posición, los vanguardistas estaban dispuestos a formar un frente común contra Somoza.

Así, se produjo "en el Alto de Ochomogo (zona ocupada por los figueristas) la entrevista personal del compañero Mora con Figueres. Llegaron al acuerdo de poner incluso inmediato fin a la guerra para hacer la resistencia posible a Somoza”. Según los vanguardistas, la deposición de las armas fue negociada por Manuel Mora y Benjamín Núñez a partir de un conjunto de garantías que habrían sido explicadas en una carta firmada por Nuñez y dirigida a Mora. En dicha carta se indicaba que el nuevo gobierno debía dar la cartera de Seguridad Pública a Miguel Brenes Gutiérrez, en quien los comunistas confiaban, y que la Secretaría de Trabajo debía recaer también en Brenes o en "un ciudadano que sea amigo de su partido el cual será debidamente consultado". Mientras tanto, "los otros puestos del Gabinete que sea preciso destituir, serán ocupados por personas de mentalidad progresista de manera que, el nuevo gobierno sea una garantía para la clase trabajadora y para el pueblo". Por si fuera poco, los figueristas hacían saber a los comunistas que su interés era formar una Constituyente con el fin de proclamar una nueva Constitución Política y por eso querían que los vanguardistas participaran tanto en la redacción de la nueva constitución como en la Constituyente.

Inmediatamente, Núñez habría indicado que no existía una justificación para el "choque sangriento" entre vanguardistas y figueristas, ya que ambos grupos podían colaborar en la realización de "los ideales más sentidos por nuestra clase trabajadora y por nuestro pueblo". Finalmente, Núñez, "siguiendo instrucciones del señor Figueres", habría adjuntado a esa carta un pliego de garantías para la clase trabajadora en el que se sostenía que: las Garantías Sociales serían respetadas y profundizadas; el Código de Trabajo no sufriría cambios en contra de los 84 Comisión Política de Vanguardia Popular, Los Sucesos de Costa Rica, p. 24. 
trabajadores sino que sería "perfeccionado a favor de los mismos"; se darían garantías para el sostenimiento y actividades de las centrales sindicales existentes en el país, la Rerum Novarum y la Confederación de Trabajadores de Costa Rica, las cuales recibirían incluso el “apoyo económico y moral" del Gobierno; el sistema de Seguros Sociales sería respetado y reestructurado para que fuera controlado por un organismo único y para que sus beneficios fueran extendidos a todos los trabajadores del país; se intensificaría el plan de viviendas baratas; se procuraría asegurar la alimentación adecuada de la población; se guardaría absoluto y efectivo "respeto al sistema democrático republicano asegurando y respetando las libertades de pensamiento, de conciencia, de palabra, de reunión y de organización a todos los partidos que existan o puedan establecerse en el país"; se sostendría el Impuesto de la Renta y se utilizaría para enfrentar las necesidades del pueblo; se produciría un programa de distribución de tierras y todas las familias de las víctimas e incapacitados de la guerra civil, sin distinción de partidos políticos, recibirían indemnizaciones adecuadas, a la vez que se garantizaba la reinserción en sus trabajos de los trabajadores que hubiesen participado en la guerra, sin distinción de bandos. ${ }^{85}$

En 1955 hay un cambio en la memoria comunista con respecto a estas garantías. Si en 1948 los vanguardistas afirmaban que el pliego de garantías venía adjuntado a la carta de Núñez como una orden de Figueres, siete años después esas garantías, en el mismo orden, se le adjudican a Manuel Mora. De acuerdo con esta versión, al ser requerido en la embajada mexicana, Mora, después de escuchar que Picado había dimitido con la promesa de que se respetarían las vidas y haciendas de los "anti-figueristas", planteó que él no podía desarmar a los militantes comunistas que estaban en lucha sin antes conseguir la promesa de que se respetarían esos compromisos. Por eso es que, según este folleto, Mora decidió subir a Ochomogo a dialogar con Figueres quien habría girado órdenes a Núñez para firmar en nombre del Ejército de Liberación la carta con 85 Comisión Política de Vanguardia Popular, Los Sucesos de Costa Rica, pp. 24-27. 
las garantías en la embajada mexicana. ${ }^{86}$ No hay en esta nueva versión una mención a alguna invitación de Figueres o Núñez para que los vanguardistas contribuyeran en la redacción de la nueva constitución política o en la Constituyente. Al contrario, los comunistas aseguran que ellos le plantearon a los líderes calderonistas participar en las elecciones para la Constituyente en 1949, garantizándoles también sus votos, con el fin de hacer más apabullante la derrota de Figueres. $^{87}$

En 1958 Manuel Mora reafirma la narración de que el pliego de garantías fue presentado por él a Figueres en Ochomogo. Según Mora, Figueres aceptó sus condiciones "las cuales, al día siguiente, fueron incorporadas al Pacto de la Embajada de México". ${ }^{88}$ Este testimonio es rescatado por Mora en 1965, ${ }^{89}$ por Adolfo Herrera, Enrique Mora y Francisco Gamboa en $1968^{90}$ y otra vez por Mora en 1969 y en $1977 .{ }^{91}$

En 1981 el periodista Miguel Salguero publicó una nueva entrevista con Manuel Mora. En esta conversación, el líder comunista transforma un tanto su relato sobre su conversación con Figueres en Ochomogo. Al ser consultado por Salguero sobre cómo estaban los ánimos en esa reunión, Mora agrega un elemento fundamental que no había incorporado en el pasado: "Figueres y yo habíamos sido amigos; y como yo le dije al comienzo de estas conversaciones, yo había sido hasta abogado de él. No fue afectuosa, pero tampoco hostil. Eran dos viejos amigos que se

$86 \quad$ Fallas, Mora y Ferreto, Calderón Guardia, José Figueres y Otilio Ulate a la luz de los últimos acontecimientos políticos, pp. 9-10.

87 Fallas, Mora y Ferreto, Calderón Guardia, José Figueres y Otilio Ulate a la luz de los últimos acontecimientos políticos, pp. 15-16.

$88 \quad$ Mora, Dos discursos en defensa de Vanguardia Popular, p. 27.

89 Manuel Mora, “¿Por qué subí a Ochomogo?”, en Libertad, 21 de agosto de 1965, p. 3.

90 Adolfo Herrera García, Enrique Mora V. y Francisco Gamboa G., Apuntes para la historia del Partido Comunista de Costa Rica (S.L., S.E., 1968), pp. 31-32.

91 Mora, 2 cartas de Manuel Mora a Calderón Guardia y José Figueres, pp. 19-22; Villegas Hoffmeister, El gobierno sobre las armas, pp. 239-243. 
encontraban de nuevo...."92 Según esta revelación, no eran dos enemigos los que se encontraban en Ochomogo, sino, dos amigos en frentes distintos. ${ }^{93}$

La primera vez que la versión de Mora sobre el Pacto de Ochomogo fue expuesta por una persona ajena a los comunistas, ocurrió como parte de dos entrevistas que el 20 y el 27 de setiembre de 1967, el sacerdote Benjamín Núñez le concedió al entonces joven tesiario en historia Oscar Aguilar Bulgarelli. Lo relatado por Núñez a Aguilar es muy importante no sólo porque tiende a confirmar la narrativa comunista que se estaba consolidando en la década de 1960, sino porque, como se verá más adelante, en la década de 1980 Núñez cambiará su versión de los hechos. Así, el sacerdote figuerista le contó al joven tesiario que en las entrevistas que se dieron en la Embajada de México para lograr un acuerdo de paz, Manuel Mora divergió con respecto a lo que los otros grupos oficialistas pretendían asegurar. Núñez dice entonces:

"Vanguardia Popular no me habló de seguridad de vidas, directamente, ni seguridad de haciendas, ellos son gentes que no tienen haciendas y no tienen por qué preocuparse por eso; pero me hablaron de algo, a mi entender, más importante, aparte de las vidas desde luego, que era el mantenimiento de las garantías sociales, el Código de Trabajo, y las instituciones sociales como el Seguro Social y el respeto a los movimientos sindicales y hasta a la existencia y a la participación política, de este grupo en la vida nacional. Yo no tuve ninguna dificultad en conceder, suscribir un documento, en que se le podía conceder a Manuel Mora, a Vanguardia Popular, esa garantía... ni Calderón Guardia, ni Teodoro

92 "Manuel Mora: su partido, sus luchas", en Miguel Salguero, Tres meses con la vida en un hilo (San José: EUNED, 1981), pp. 127-176, cita p. 176.

93 En otra parte, Mora habría revelado que camino a Ochomogo, "recordaba aquellas noches por el camino de La Lucha las veces que Figueres me había llevado en motocicleta a darles conferencias a sus peones, años atrás”, Salas, Con Manuel, p. 171. 
Picado, me hablaron de esas garantías; en ningún momento mencionaron el Código de Trabajo, ni el Seguro Social, ni el sindicalismo. Quien me habló, muy interesado, como punto central de la negociación, fue Manuel Mora, él quería que esas instituciones sociales, se mantuvieran incólumes y se robustecieran". 94

Pero esta narración cambia abruptamente en un momento. Así Núñez indica que: “Cuando estábamos en esas conversaciones se presentó una situación muy seria, y sentí que ya no me encontraba capacitado para seguir la conversación por mí mismo". ${ }^{95}$ ¿Cuál era esa seria situación de la que hablaba el sacerdote? Núñez no indica a qué se refiere. Más adelante descarta que como telón de fondo a esta conversación con Mora se presentara el peligro de una invasión nicaragüense o estadounidense al país, destacando que la noche en que él, Mora y Figueres se reunieron en Ochomogo, solamente se mencionó la amenaza somocista, "que todavía no se había hecho real". ${ }^{96}$ Según Núñez, la conversación entre Mora y Figueres en Ochomogo fue un intento de ambas partes por convencerse mutuamente:

"Manuel Mora quería convencer a Figueres de la conveniencia de la concesión de las garantías, del carácter de las Garantías Sociales, de la Legislación Social, de las instituciones sociales, el reconocimiento de la vida política de su partido. Por otro lado Figueres quería convencer a Manuel Mora, que no había razón de que los comunistas nos estuvieran combatiendo... No terminamos en nada... Por tanto no hubo ahí ningún

94 “Anexo No. 10. Entrevista con el Pbro. Benjamín Núñez Vargas-No. 1”, Oscar Aguilar Bulgarelli, Costa Rica y sus hechos políticos de 1948. Problemática de una década (San José: Editorial Costa Rica, tercera edición 1978), p. 595.

95 Aguilar Bulgarelli, Costa Rica y sus hechos políticos de 1948, p. 596.

96 Aguilar Bulgarelli, Costa Rica y sus hechos políticos de 1948, p. 602. 
pacto, ningún arreglo, cada uno contó sus intenciones y trató de ganar al otro para su causa, y nada más. Por eso es equivocado hablar del Pacto de Ochomogo, no hubo ningún pacto". 97

En el testimonio de Núñez, contrario a lo que ocurre en el de su contraparte comunista, la amenaza somocista no aparece sino hasta después de la reunión en Ochomogo. Pero no va ser esta invasión la que convenza al sacerdote oposicionista de finiquitar las negociaciones en la embajada. Es en este punto del relato de Núñez en donde aparece la "situación muy seria" que habría aparecido antes de tiempo en su entrevista con Aguilar. Así, el cura le indicó a Aguilar que:

“Un día vino otro señor de origen español, don Enrique Limosner, a la Embajada de México, y preocupado comunicó a los embajadores el hecho de que en el entonces edificio de aviación que está al final del Paseo Colón se había almacenado una gran cantidad de dinamita y que se quería hacer en San José el tipo de defensa parecido al que se había hecho en Madrid, y dijo que el que estaba al frente de ese plan era el señor López Masegoza. El señor Limosner llevó a dos diplomáticos a que fueran a ver lo que él les estaba diciendo. Ellos fueron y comprobaron que en el edificio de La Sabana, según dijeron, había una extraordinaria cantidad de dinamita, y López Masegoza declaró abiertamente que esa dinamita era para librar la batalla de San José, que no se rendirían y que iban a demostrarle a Figueres lo que era pelear en la ciudad, y que ahí iban a destruir el mito que era Figueres... Este informe de la disposición que había de defender San José como a Madrid era grave y era toda una amenaza, porque manifestaba el ánimo caldeado

97 Aguilar Bulgarelli, Costa Rica y sus hechos políticos de 1948, pp. 601-603. 
de grandes sectores... En todo caso mi tarea era evitar, —por lo menos lo concebí así y creo que lo volvería a hacer-, que esa lucha tuviera lugar y favorecer con cuidado todos los planteamientos que se hicieran para evitar esa lucha en San José, que iría a costar tanta vida inocente, de personas que no estaban envueltas en el conflicto, tanta destrucción física, material. Fue de ahí en adelante que entendí con más claridad que había que agotar todos los medios para que se llegara a un arreglo. Este era el hecho que yo quería anotar, pues trajo un momento de dramatismo, casi trágico en el proceso de las conversaciones". ${ }^{98}$

Es en este contexto, de acuerdo con Núñez, que él decidió negociar con Manuel Mora lo que el líder comunista insistentemente pedía. Así, el sacerdote figuerista le indicó a Aguilar que:

"De lo que ellos sólo hablaban... era de que se mantuvieran las garantías sociales, las instituciones sociales, la posibilidad de acción de su grupo, en el orden político que surgiera a raíz del arreglo. En cuanto a los dos primeros puntos ya lo habíamos conversado en el Alto de Ochomogo, y como Manuel Mora insistiera en esa parte yo escribí un documento especial dirigido a Vanguardia Popular, en que yo les aseguraba el mantenimiento de esas garantías, aseguraba también la posibilidad de que se impulsaría más y más la reforma social... Esa misma mañana entregué el documento a Manuel Mora". ${ }^{99}$

De esa manera el testimonio de Núñez de 1967 agrega nuevos elementos a la narrativa 98 “Anexo No. 11. Entrevista No. 2 con el Presbo. Benjamín Núñez Vargas”, Aguilar Bulgarelli, Costa Rica y sus hechos políticos de 1948, pp. 610-612.

99 Aguilar Bulgarelli, Costa Rica y sus hechos políticos de 1948, pp. 613-614. 
comunista sobre el Pacto de Ochomogo y parece confirmar uno de los puntos medulares defendidos por Manuel Mora: la existencia de una carta y de un pliego de peticiones que habrían convencido a los vanguardistas de su rendición. Pero el testimonio de Núñez parecer haber persuadido más al joven Aguilar Bulgarelli quien escribió en su análisis de la Guerra Civil que en Ochomogo "no se firmó ningún pacto" y solamente fue "un cambio de ideas, en que se trató de mostrar al líder Mora que la oposición de su partido a la acción de Figueres, no tenía razón de ser”. El convencimiento del joven tesiario es precedido por una afirmación más fuerte sobre la narración de Vanguardia Popular acerca de la necesidad de dialogar con Figueres debido a la invasión que sufría el país: “Esto es falso porque aquella conversación se realizó antes de la invasión a que hacemos referencia". ${ }^{100}$ La incredulidad de Aguilar sobre lo apuntado por Mora acerca del pacto en Ochomogo, tenía sin embargo un trasfondo más amplio en el que las narrativas comunistas se enfrentaban con otras memorias.

\section{Narrativas rotas}

El folleto de 1955 publicado por Fallas, Mora y Ferreto agrega un elemento inusual al testimonio comunista sobre el final del conflicto. Enfrentados a una crítica pública venida desde el ulatismo, los vanguardistas se vieron sometidos a una acusación que aseguraba que había existido un pacto secreto entre Manuel Mora y José Figueres en 1948, en vista del cual los comunistas se habían vendido a los figueristas. Los izquierdistas enfrentaron este cuestionamiento diciendo que el gobierno transitorio posterior a la Guerra Civil le otorgó a Manuel Mora 250.000 colones, "para licenciar más o menos tres mil milicianos vanguardistas” y para repartir entre los numerosos soldados y voluntarios que permanecían en los cuarteles del gobierno. Los comunistas afirman 100 Aguilar Bulgarelli, Costa Rica y sus hechos políticos de 1948, p. 366. 
haber repartido ese dinero equitativamente entre los grupos señalados y denuncian que: “ Este dinero es el dinero que algunos mal intencionados afirman que sirvió para comprar a los dirigentes de Vanguardia Popular, y que otros dicen que Manuel Mora se llevó para México!". ${ }^{101}$

Será Otilio Ulate quien llevará esta crítica más allá en $1955 .{ }^{102}$ En ese año, en el contexto de la segunda invasión calderonista a Costa Rica desde Nicaragua, Ulate publicó en el Diario de Costa Rica una serie de artículos enfrentando al entonces presidente Figueres, quien lo había vinculado públicamente con la invasión. Estos artículos luego fueron reunidos por un grupo de amigos políticos ${ }^{103}$ de Ulate con el título ¿Hacia a dónde lleva a Costa Rica el señor presidente Figueres? En uno de los textos allí reunidos Ulate indicaba que:

"Si bien se ha explotado mucho para los efectos de la propaganda en el exterior, el hecho de que al ser derrocado el Gobierno de Picado en abril de 1948, fue desplazado del poder el Partido Comunista, la realidad es que lo fue por accidente y que luego se trató de atraer al Partido Vanguardia Popular a cooperar con el Partido Liberación Nacional, o, cuando menos, se le hicieron ofertas, inmediatamente después de su caída, para ganar la buena voluntad de los comunistas". ${ }^{104}$

101 Fallas, Mora y Ferreto, Calderón Guardia, José Figueres y Otilio Ulate a la luz de los últimos acontecimientos políticos, p. 12.

102 En ese mismo año aparece la crítica de Otilio Ulate a la ya para entonces llamada "generación del 48". Esta crítica la escribió Ulate como una reacción a su lectura del libro de Alberto Cañas, Los 8 años. Otilio Ulate, La Generación del 48 enjuiciada por Otilio Ulate (San José: Comisión Nacional de Conmemoraciones Históricas, 1992).

103 En realidad se identifican en el texto como un "grupo de ciudadanos vigilantes y preocupados". Los nombres de esos ciudadanos eran: José Joaquín Jiménez Núñez, Juan Trejos Quirós, Joaquín Cabezas Duffner, Alberto Oreamuno Flores, Abelardo Bonilla B., Fernando Lara Bustamante y Ricardo Esquivel Fernández.

104 Otilio Ulate, ¿Hacia a dónde lleva a Costa Rica el señor presidente Figueres? (S.L., S.E., 1955), p. 16. 
De acuerdo con Ulate, el sacerdote Benjamín Núñez y José Figueres habían tenido “buenas relaciones personales" con Manuel Mora, las cuales se basaban en "similitudes ideológicas". Dichas relaciones habrían permitido negociar el armisticio a los líderes mencionados. En este punto, Ulate reproduce la carta firmada por Núñez el 19 de abril de 1948 y el pliego de peticiones ya mencionado, pero indicando que su acceso a esos documentos se produjo gracias a que durante su paso por Panamá hacia el exilio en 1948, Mora fue requisado por las autoridades panameñas quienes tomaron copias de esos documentos. Desde la perspectiva de Ulate, esos documentos probaban un pacto secreto entre Figueres y Mora que no pudo ser consumado completamente porque hubo una presión muy fuerte de parte de la "voluntad popular". ${ }^{105}$

La estrategia de Ulate de vincular a Figueres con los comunistas podía ser funcional en el contexto de la Guerra Fría, aunque está claro que Figueres jugó mejor ese juego durante la década de $1950 .{ }^{106}$ Empero, la versión de que existió un pacto secreto entre Figueres y Mora en Ochomogo continúo recuperándose. Lo más interesante es que quien llevará a su máxima expresión esa acusación será uno de los líderes más importantes del comunismo costarricense: el profesor Arnoldo Ferreto.

El antecedente de este cambio en el testimonio de Ferreto se presenta como una reacción a la aparición del libro de Figueres que reúne sus memorias sobre la Guerra Civil: El Espíritu del 48. Al acercarse a la narración de su reunión con Manuel Mora en Ochomogo y lo que allí se discutió, Figueres indica:

105 Ulate, ¿Hacia a dónde lleva a Costa Rica el señor presidente Figueres?, p. 17.

106 Kyle Longley, The Sparrow and the Hawk: Costa Rica and the United States during the Rise of José Figueres (Tuscaloosa: University of Alabama Press, 1997), pp. 142-152 y Kirk S. Bowman, “¿Fue el compromiso y consenso de las elites lo que llevó a la consolidación democrática en Costa Rica? Evidencia de la década de 1950" en Revista de Historia, No. 41 (enero-junio, 2000), pp. 91-127. 
“Sobre esta entrevista, que yo considero sagrada, mucho se ha especulado y mucho se ha mentido. Los llamados historiadores, le han agregado compromisos que no hubo en ella. Los políticos irresponsables la han tratado de presentar de modo que aprovechara a sus intereses. Igual si son de derecha, que de izquierda. Interesadamente, han hecho surgir de ese encuentro, compromisos que nunca se establecieron. Han llegado a violentar la verdad, diciendo que en Ochomogo se firmó un pacto entre los comunistas y yo. Falso. ¡En Ochomogo no suscribimos ni acordamos pacto alguno!...

Lo que se habló en Ochomogo sirvió como base para un documento, que facilitaría el arribo a la paz, a la hora de firmar lo que inexactamente se ha llamado el Pacto de la Embajada de México, que puso fin a las hostilidades.

Precisamente, cuando regresábamos a nuestras líneas, autoricé al Padre Núñez, para que si era menester, suscribiera algún documento, en que se fijara nuestra posición ante la cuestión social”. ${ }^{107}$

Figueres insiste, en ese sentido, en el hilo conductor del testimonio que había construido Núñez en 1967. Justamente, es Núñez a quien invita Figueres a escribir acerca de los documentos

107 José Figueres, El Espíritu del 48 (San José: Editorial Costa Rica, 1987), pp. 264-265. Las cursivas son del original. La crítica a la forma en que los historiadores profesionales han interpretado la década de 1940 y la Guerra Civil de 1948 es común entre los protagonistas cercanos a, o militantes de, Liberación Nacional. Por ejemplo, al presentar un libro sobre la década de 1940 del periodista liberacionista Guillermo Villegas, Alberto Cañas señalaba que ese texto era una reacción a "la especulación archivológica" y a las "interpretaciones ideológicas interesadas que algunos han ensayado, las cuales se quedan cortas ante la realidad, monda y lironda". Aunque no cita ningún ejemplo de eso que crítica, Cañas todavía argumenta que Figueres decía que: "Nosotros hicimos la historia; ellos se están limitando a escribirla, y nos la están escribiendo como les da la gana". Guillermo Villegas Hoffmeister, La guerra de Figueres. Crónica de ocho años (San José: EUNED, 1998), pp. xi-xii. Para una vigorosa crítica al libro de Villegas ver: Iván Molina Jiménez, “¿De vuelta a los Ocho Años’ A propósito de La Guerra de Figueres de Guillermo Villegas Hoffmeister", en Revista de Historia (Costa Rica), No. 41 (enero-junio del 2000), pp. 191-198. 
firmados en la Embajada de México el 19 de abril, especialmente refiriéndose a "una carta, cuya firma se atribuye al Padre Núñez y que se ha hecho circular, como si ella contuviese promesas de orden político, hechas por nosotros al Partido Vanguardia Popular". ${ }^{108}$ La existencia de tal carta es tan importante en el testimonio de Figueres como lo es en el de Manuel Mora. Dicha misiva es la misma que en 1948 la CPPVP presentó como la introducción al pliego de peticiones en donde se declaraba el respeto a la legislación social. Figueres reconoce la existencia de ese pliego, pero como parte de los documentos firmados en la Embajada de México ${ }^{109}$ y no como un contrato particular entre Vanguardia Popular y el grupo rebelde, al que se habría adjuntado la carta atribuida por los comunistas a Figueres y firmada por Núñez. Al respecto, en el "informe escrito" que Núñez escribió para Figueres sobre el origen y validez de esa misiva, el sacerdote señala:

“Cuando estábamos almorzando, al mediodía del 19 de Abril de 1948, en la Embajada de México, se presentó repentinamente el dirigente comunista Arnoldo Ferreto, quien llamó a Manuel Mora, que estaba sentado a nuestra mesa. Salieron los dos y conversaron por un breve rato. Luego vino Manuel Mora me dijo que el Buró Político de su partido, no

108 Figueres, El Espíritu del 48, p. 275. En una entrevista que le hizo el historiador Gerardo Contreras a Figueres en abril de 1983, el líder liberacionista ya se había referido a la carta firmada por Núñez. Figueres dice: "Tanto el Padre Núñez como don Manuel Mora admitieron que esa carta se suscribió solamente en un momento de angustia para tranquilizar a la gente de don Manuel Mora, en el entendido de que eso no era el compromiso definitivo que ahí se decía, sino un paso para llegar a las conversaciones directas entre don Manuel y yo, y llegar a algún entendimiento de paz. Después por razones políticas don Otilio se empeñó en que esta carta había sido escrita con toda intención de que se cumpliera, lo cual no resultó cierto de parte del Padre Núñez ni de don Manuel Mora". Gerardo Contreras, "Entrevista realizada a don José Figueres Ferrer, presidente del Partido Liberación Nacional", 19 de abril de 1983, p. 3. Agradezco profundamente al profesor Contreras por facilitarme la copia de esta entrevista.

Figueres, El Espíritu del 48, pp. 273-274. 
aceptaba los términos del Arreglo Preliminar, que se había acordado hasta ese momento y que se iba a firmar dentro de una hora. La dirigencia comunista, estaba dispuesta a seguir luchando, aunque los demás se rindieran. Le manifesté que poco podía hacer yo en esa situación. Me asustaba lo que podría pasar de allí en adelante. Don Manuel me dijo entonces, que había un medio para tranquilizar al Buró Político. Me pidió que le firmara una carta, que él iba a redactar, en la que aparentemente el Ejército de Liberación Nacional y desde luego don Pepe, cuyo representante yo era, les ofreciera ciertas concesiones políticas. Reaccioné diciéndole que tal ofrecimiento sobrepasaba la plenipotencia de mi delegación. Que una cosa de tanta monta, exigía una consulta a Don Pepe y al Ejército de Liberación Nacional. Don Manuel me pidió unos minutos para redactar la carta, cuyo texto, según él, contendría cosas inocuas. Yo le concedí el tiempo que pedía.

Después de algunos minutos, regresó don Manuel, trayéndome un proyecto de carta, en la que me hacía prometer que al organizar el nuevo Gobierno resultante de la Revolución, a su partido, se le darían ciertas garantías, nombrando dentro del Gobierno, a personas de mentalidad progresista; que a los comunistas se les consultaría en la elaboración de la nueva Carta Constitucional, y se les daría participación en la Constituyente. Don Manuel incluía un ruego de precaución: tener este documento como privado". ${ }^{110}$

Según Núñez, él se negó rotundamente a firmar esa carta porque no iba a tener ningún valor para Figueres ni para sus seguidores. Entonces Mora volvió a la carga argumentando que él necesitaba ese documento para convencer al Buró Político de Vanguardia Popular de deponer las armas. Núñez relata que Mora le habría pedido entonces su firma recalcándole que no involucraba ningún compromiso moral para el sacerdote ni para Figueres. De acuerdo con Núñez, el líder 110 Figueres, El Espíritu del 48, pp. 275-276. La negrita es del original. 
comunista le habría dicho: "Necesito ese papel únicamente, para evitar una hecatombe, haciendo creer a mis compañeros de dirección, que se les han concedido las condiciones que están exigiendo". ${ }^{111}$ Esta propuesta, en la memoria de Núñez, condujo al sacerdote a una valoración en la que salió ganando su deseo por evitar una fuerte lucha en San José, incluso a riesgo de prestarse al "engaño" o "jugarreta política" que Mora le estaba haciendo a su propio partido. Núñez, por tanto, habría firmado el documento enfatizando nuevamente al líder comunista que esa carta era un documento apócrifo y no tenía, "ni podrá tener nunca, valor obligante". El sacerdote dice: "Don Manuel asintió totalmente a mis afirmaciones. Puse mi nombre al pie de la carta. Don Manuel me prometió devolvérmela apenas volviera de convencer a sus compañeros con ella". ${ }^{112}$

La narración de Núñez, un tanto diferente de lo que le contó a Aguilar Bulgarelli en 1967, dejó en entredicho la versión de Manuel Mora de forma más fuerte que lo que había hecho la crítica de Ulate en la década de 1950. En este testimonio, a pesar de la insistencia del sacerdote en que Mora habría engañado a su partido por motivos patrióticos, el líder comunista aparece como traidor a su organización política. Por eso, la nueva narrativa del cura socialdemócrata caería como una bomba en la memoria comunista que ya arrastraba ciertas dudas sobre lo ocurrido en Ochomogo.

Al respecto, en junio de 1950, en su informe al Sétimo Congreso del Partido Vanguardia Popular, organizado en la clandestinidad, Arnoldo Ferreto ya había mostrado dudas sobre la actuación de Mora. Después de analizar el problema fundamental que en su perspectiva involucró el protagonismo de Mora en las negociaciones en la Embajada de México, Ferreto la emprendió contra la extrema confianza que tuvieron los comunistas en el arreglo pactado entre

$111 \quad$ Figueres, El Espiritu del 48, p. 277.

112 Figueres, El Espiritu del 48, pp. 277-278. 
Mora y Figueres. Ferreto recalcó entonces las "falsas ilusiones" que creó entre los combatientes vanguardistas el respeto de Figueres hacia los compromisos que asumió en los documentos conducentes a la negociación del final del conflicto bélico. En su juzgamiento de la extrema confianza de Mora, Ferreto además revela una discusión posterior que da más luces sobre la cuestión del Pacto de Ochomogo y su ligamen con el desarme de los vanguardistas:

"El c. Mora basó en parte su confianza en los acuerdos en consideraciones de orden puramente subjetivo. En otras palabras, el concepto personal que el c. Mora tenía de José Figueres y del cura Núñez, particularmente del primero, influyó en su determinación... Aunque muchos de los demás dirigentes del Partido no participábamos del concepto personal que el c. Mora tenía de Figueres, es lo cierto que ninguno tuvo visión clasista del problema.

...Por otra parte, se ha dicho que si nosotros hubiéramos visto claro, que si hubiéramos enfocado objetivamente la situación, siempre hubiéramos tenido que hacer lo mismo.

...Otros plantean una cuestión más concreta y dice 'Si aun después de obtener 'garantías' complementarias de parte de Figueres, garantías que el c. Mora hizo públicas en sendos discursos, fue tarea harto difícil desarmar a nuestras fuerzas, ¿cómo se hubieran podido desarmar sin tales 'garantías' complementarias, es decir, si denunciamos desde el primer momento el valor nulo de todos los compromisos de Figueres con Teodoro Picado y nos negamos a negociar por nuestra parte compromisos complementarios?"113

De acuerdo con el informe de Ferreto, desde el principio varios líderes comunistas

113 Ferreto, "Informe sobre la situación política nacional; antecedentes y perspectivas", pp. $135-136$. 
dudaban de que el acuerdo con los oposicionistas, construido básicamente teniendo como garantía la amistad que unía a Mora con Figueres, fuese a cumplirse. Esta cuestión tiene una narración paralela en las memorias de Ferreto. ${ }^{114}$ En ellas, publicadas en 1984, el líder comunista resalta los conflictos que produjo en el seno del Partido Comunista la negociación de Mora con Núñez y Figueres. Según Ferreto:

“Este Pacto, que recibió el nombre de 'Ochomogo', no obtuvo la aprobación previa de la dirección del Partido, ni tampoco su expreso repudio, pues las circunstancias no lo permitieron, pero los hechos estaban consumados, la suerte echada y no hubo más remedio que hacer frente a lo que viniera.

Después de firmado por Mora el 'Pacto de Ochomogo', en horas de la noche se reunió, en el anexo del Hotel Costa Rica, donde el Partido tenía su cuartel general, la Comisión Política del Comité Central junto con algunos cuadros militares de las fuerzas armadas bajo nuestro control. En esa reunión Manuel Mora Valverde informó sobre lo que había pactado. La reunión, como es de suponer, se celebró en un ambiente de extrema tensión y de cansancio. Hubo en ella fuertes recriminaciones por la forma personal en que Manuel resolvió asuntos tan graves, aduciendo éste, en su descargo, que después de haber capitulado Teodoro Picado ante el Cuerpo Diplomático en la Embajada de México, no

114 Sin embargo, es importante señalar que en tres entrevistas concedidas en 1982, Ferreto apoya la imagen que se había creado de Manuel Mora como leal y sincero líder del comunismo costarricense. Gerardo Contreras, "Entrevista al Prof. Arnoldo Ferreto, dirigente del Partido Vanguardia Popular. Tema: Antecedentes de la alianza Partido Vanguardia Popular y Partido Republicano Nacional", 2 de junio de 1982; ídem, "Entrevista al Prof. Arnoldo Ferreto, dirigente del Partido Vanguardia Popular. Tema: periodo de don Teodoro Picado", 27 de octubre de 1982; ídem, "Entrevista realizada a don José Figueres Ferrer, presidente del Partido Liberación Nacional", 19 de abril de 1983, p. 3. Agradezco profundamente al profesor Contreras las copias de estas valiosas entrevistas. 
nos quedaba a nosotros más alternativa que aceptar dicha capitulación y tratar de obtener algunas garantías relacionadas con la seguridad de los miembros del Partido y de sus combatientes.

El compañero Luis Carballo dejó caer la pregunta que no tuvo respuesta: ¿Quién autorizó al compañero Mora a negociar y pactar con Figueres?

En el pacto, Mora se comprometió a desarmar a nuestras tropas y entregar las armas al gobierno de facto.

Durante la violenta discusión que tuvo lugar aquella noche en el anexo del Hotel Costa Rica, Mora expresó que debíamos confiar en las promesas de Figueres, y que la garantía de ese cumplimiento era el Cuerpo Diplomático. Más tarde pudimos comprobar, en la práctica, que tuvieron razón los camaradas que alegaron que esa garantía no tenía valor alguno". 115

Al insistir, casi cincuenta años después, en someter a juicio las acciones de Mora en 1948, Ferreto rompe con la memoria partidista que instaba a mirar lo hecho por Mora como parte de un consenso dentro del Partido. En esta versión, Mora ya no actúa más como el líder supremo de los vanguardistas, ni como la expresión de su pensamiento y accionar, sino que se presenta saltándose la línea de toma de decisiones de la CPPVP e, incluso, actuando ilegalmente según los estatutos del partido. Así, en las memorias de Ferreto ya no se presenta al Partido Vanguardia Popular como unívoco, sino cuestionando la participación de Mora en los acuerdos de la Embajada de México y discutiendo hasta el cansancio su proceder. Esa discusión incluso involucra la duda acerca de los motivos existentes detrás de la confianza de Mora en Figueres. Esta desconfianza ubicada en el pasado, prontamente es traída al presente por Ferreto. Así, en 115 Ferreto, Vida Militante, pp. 98-99. 
un libro publicado en 1987, Ferreto somete a juicio todas las acciones emprendidas por Manuel Mora durante la Guerra Civil, afirmando que Mora:

“asistió a las reuniones de la Embajada sin siquiera informar a la Dirección del Partido de lo que se estaba tramando... Manuel Mora acordó, por su cuenta y riesgo, que el Partido depusiera las armas y las entregara al enemigo. Esto ocurrió después de haber sido prevenido por mí de que la Comisión Política del CC se negaba a que se depusieran las armas en los términos convenidos por el Presidente Picado. Como el Partido se resistía, se dispuso celebrar una reunión que duró toda la noche, en el anexo del Hotel Costa Rica. Manuel Mora presentó el supuesto 'Pacto de Ochomogo' con las conocidas promesas políticas y sociales que fueron violadas de principio a fin. El plenipotenciario de Figueres, presbítero Benjamín Núñez, afirma que ese 'Pacto' no existió y que fue un engaño deliberado. En su libro 'El Espíritu del 48', Figueres endosa esta afirmación... ".116

La grieta en las memorias comunistas estaba ya abierta y no se cerraría. El contexto de fondo de esta discusión fue la crisis y división del Partido Comunista entre 1982 y 1984, un proceso en el que se enfrentaron Ferreto y Mora acompañados por sus respectivos grupos partidarios. ${ }^{117}$ En la lucha citada, el pasado se convirtió en una herramienta fundamental para

116 Arnoldo Ferreto, Gestación, consecuencias y desarrollo de los sucesos de 1948. Ensayo sobre la historia del Partido Vanguardia Popular (San José: Ediciones Zúñiga y Cabal, 1987), pp. 36-37.

117 Roberto Salom, La crisis de la izquierda en Costa Rica (San José: Editorial Porvenir, 1987), pp. 66-75; Gerardo Contreras, La historia no es color de rosa. A propósito del setenta y cinco aniversario de la fundación del Partido Comunista de Costa Rica (San José: Ediciones Perro Azul, 2006), pp. 146-165. 
legitimar o deslegitimar la manera en que cada grupo reclamaba para sí el ser la representación histórica del comunismo costarricense. Y, por supuesto, esa discusión también sirvió para que la fisura de las memorias comunistas sobre la Guerra Civil de 1948 se terminara de consolidar. Así, en una entrevista concedida en 1990, Ferreto profundizó sus críticas, afirmando que desde 1943 Manuel Mora se comenzó a alejar de los ideales que motivaban a los comunistas. Desde esa nueva perspectiva, Mora se habría preocupado no sólo por cambiar el nombre del partido a Vanguardia Popular, sino que también habría tratado de que sus compañeros renunciaran a su identidad comunista. ${ }^{118}$

El primer cuestionamiento al testimonio ofrecido por Núñez lo realizó el hermano de Manuel Mora y también dirigente comunista: Eduardo Mora. Para él, la narrativa de Núñez podía interpretarse políticamente como un intento "para crear seguramente mayores motivos de roces en la izquierda". ${ }^{119}$ La defensa histórica empero, sería emprendida con más ahínco por José Merino del Río, quien en un libro publicado en 1996 recupera el relato de Mora y trata de enfrentarlo al que Núñez le presentó a Figueres. De esa confrontación Merino destaca la existencia de "un importante campo de coincidencias entre los partidos de Mora y Figueres", que habría facilitado el pacto entre ellas. Por eso, en esta perspectiva, la amistad de Figueres y Mora parece interpretarse en términos ideológicos. Además, la posterior ilegalización de la izquierda es entendida por Merino de acuerdo al testimonio histórico de los comunistas, es decir, como una táctica para hacerle concesiones al imperialismo estadounidense. Pero lo que realmente convence a Merino de la veracidad del testimonio de Mora es un documental producido en 1979 por el

118 "Entrevista a Arnoldo Ferreto", Archivo Nacional de Costa Rica, Serie Casetes, Nos. 253-254, 7 de setiembre de 1990.

119 Eduardo Mora incluso pone en duda que el verdadero autor del libro El Espíritu del 48 sea Figueres sino el mismo Núñez junto con el periodista Guillermo Villegas. Eduardo Mora Valverde, De Sandino a Stalin (San José: Editorial Revolución, 1988), p. 125. 
Departamento de Cine del Ministerio de Cultura en el que Figueres, Mora y Núñez reprodujeron en Ochomogo la conversación que habrían tenido aquella noche de abril de $1948 .{ }^{120}$ Su visión empero, sirvió poco para que la relectura del pasado ayudara en la reparación de un partido cuya memoria estaba mutilada. Así, frente al Pacto de Ochomogo los izquierdistas divididos continuaron desarrollando dos narrativas distintas: la que apoyaba a Manuel Mora y su testimonio y la que acusaba a Mora de haber traicionado al Partido Comunista en Ochomogo. ${ }^{121}$

\section{Conclusiones}

Las memorias comunistas sobre la Guerra Civil de 1948 han sido múltiples y cambiantes. En parte, esa heterogeneidad se escondió en buena medida durante el periodo 1948-1984 por efecto de un interés por mostrar una unidad interna dentro del Partido Comunista, tanto en su periodo de clandestinidad como después de su legalización. A esta unicidad contribuyó el que Manuel Mora fuese el vocero más importante del grupo, quien acudía a las radios y periódicos a exponer los puntos de vista comunistas sobre el pasado y a quien entrevistaban los estudiosos interesados

120 José Merino del Río, Manuel Mora y la democracia costarricense (Heredia: EFUNA, 1996), pp. 125-130. Rodolfo Cerdas también comparte la idea de que el documental citado es prueba veraz de la veracidad del testimonio de Manuel Mora. Rodolfo Cerdas Cruz, La otra cara del 48. Guerra Fría y movimiento obrero en Costa Rica 1945-1952 (San José: EUNED, 1998), pp. 51-52.

121 Esta división es visible en una entrevista que el 6 de junio de 2006 le hizo Manuel Boza al historiador Gerardo Contreras y al Secretario General del Partido Vanguardia Popular Humberto Vargas Carbonell. A pesar de que Contreras presentó la narrativa tradicional acerca del Pacto de Ochomogo, Vargas Carbonell expresó sus "enormes dudas" al respecto, dejando claro que el desarme que sucedió al pacto fue "el error más grande que cometió este Partido en toda su existencia". "A los 75 años de la fundación del Partido Comunista de Costa Rica", en http:// www.vanguardiapopular.org/documentos/2006/doc02.htm. Contreras volvió a defender lo dicho en el testimonio oficial de Manuel Mora en un artículo publicado en mayo de 2008. Gerardo Contreras, "Derrota y marginación de Vanguardia Popular", Áncora, 25 de mayo de 2008. 
en la década de 1940. Este prestigio de Mora como fuente del recuerdo, expuso públicamente al líder de la izquierda de forma tal que no sólo él tendió a personalizar el recuerdo y las principales acciones sobre sí mismo, sino que su memoria también sufrió de transformaciones sutiles que, al ser públicas, volvían más evidentes los cambios en su testimonio. Aún así, muchos de los interesados en el análisis de los acontecimientos enmarcados en la Guerra Civil, no temieron en reproducir consistentemente los recuerdos de Mora sin cuestionarlos. ${ }^{122}$

Justamente por esa dependencia en una narrativa partidista, la crisis más seria sobre el recuerdo de la Guerra Civil entre los comunistas, se produjo en el contexto de la división del partido. Ya que la trayectoria histórica se convirtió en la herramienta legitimadora del presente, los grupos de izquierdistas divididos acudieron a ella para acusar a sus contrapartes de haber traicionado el sentido original de su lucha. En esos términos, el 48, y especialmente el recuerdo del Pacto de Ochomogo, se volvió más problemático, convirtiéndose a su vez en una fuente propiciadora de la división, la enemistad y las acusaciones.

Pero las memorias comunistas tampoco dan pruebas inequívocas de una unicidad antes de la ruptura del Partido. Conforme el contexto se los exigió y a medida que sus protagonistas se alejaron de los acontecimientos, los recuerdos comunistas comenzaron a tomar vida propia y a variar dependiendo de las exigencias que enfrentaban sus productores. Así, al ser enfrentados con otras fuentes, los testimonios de la izquierda sufrían por efecto de algunas de sus ambigüedades. No obstante, los testimonios de los comunistas —y no podía ser de otra manera — han jugado un papel fundamental en el entendimiento de ese periodo histórico. Pero a la luz de lo expuesto en este trabajo, frente a la constatación de la diversidad y transformación de las memorias de los líderes vanguardistas, sucede un nuevo acercamiento a lo que ocurrió entre 1940 y 1948 en Costa

122 Iván Molina ha mostrado claramente esto en su estudio sobre las memorias de la Reforma Social. Molina, Los pasados de la memoria, capítulos 4-15. 


\section{OI $9^{\circ}$ CONGRESO \\ D CENTROAMERICANO \\ DE HISTORIA \\ Universidad de costa Rica}

Indexaciones: Repositorio de Revistas UCR, DIALNET, Latindex, REDALYC Directorio y recolector de recursos digitales del Ministerio de Cultura de España, Directory of Open Access Journals. Diálogos Revista Electrónica de Historia ISSN 1409-469X. Número especial 2008. Dirección web: http://historia.fcs.ucr.ac.cr/dialogos.htm

Rica, especialmente prestando atención al papel de las masas populares en ese impresionante proceso histórico. 